\title{
The Risk of Deterioration in GCS13-15 Patients with Traumatic Brain Injury Identified by Computed Tomography Imaging: A Systematic Review and Meta-Analysis
}

\author{
Carl Marincowitz,' Fiona E. Lecky, William Townend, \\ Aditya Borakati, ${ }^{4}$ Andrea Fabbri, ${ }^{5}$ and Trevor A. Sheldon ${ }^{6}$
}

\begin{abstract}
The optimal management of mild traumatic brain injury (TBI) patients with injuries identified by computed tomography (CT) brain scan is unclear. Some guidelines recommend hospital admission for an observation period of at least $24 \mathrm{~h}$. Others argue that selected lower-risk patients can be discharged from the Emergency Department (ED). The objective of our review and meta-analysis was to estimate the risk of death, neurosurgical intervention, and clinical deterioration in mild TBI patients with injuries identified by CT brain scan, and assess which patient factors affect the risk of these outcomes. A systematic review and meta-analysis adhering to PRISMA standards of protocol and reporting were conducted. Study selection was performed by two independent reviewers. Meta-analysis using a random effects model was undertaken to estimate pooled risks for: clinical deterioration, neurosurgical intervention, and death. Meta-regression was used to explore between-study variation in outcome estimates using study population characteristics. Forty-nine primary studies and five reviews were identified that met the inclusion criteria. The estimated pooled risk for the outcomes of interest were: clinical deterioration $11.7 \%$ (95\% confidence interval [CI]: 11.7\%-15.8\%), neurosurgical intervention 3.5\% (95\% CI: 2.2\%-4.9\%), and death $1.4 \%$ (95\% CI: $0.8 \%-2.2 \%$ ). Twenty-one studies presented within-study estimates of the effect of patient factors. Meta-regression of study characteristics and pooling of within-study estimates of risk factor effect found the following factors significantly affected the risk for adverse outcomes: age, initial Glasgow Coma Scale (GCS), type of injury, and anti-coagulation. The generalizability of many studies was limited due to population selection. Mild TBI patients with injuries identified by CT brain scan have a small but clinically important risk for serious adverse outcomes. This review has identified several prognostic factors; research is needed to derive and validate a usable clinical decision rule so that low-risk patients can be safely discharged from the ED.
\end{abstract}

Keywords: intra-cranial hemorrhage; mild traumatic brain injury; minor head injury; prognostic modeling

\section{Introduction}

$\mathbf{T}$ Here are 1.4 million annual attendances in England and Wales to Emergency Departments (EDs) following a head injury (any trauma to the head), and in 2010, 2.5 million people were treated for traumatic brain injury (TBI; injury to the brain or alteration of brain function due to an external force) in the United States. ${ }^{1}$ Approximately $95 \%$ of patients have an initial Glasgow
Coma Scale (GCS) of 13-15, out of a possible 15, indicating normal or mildly impaired responsiveness and orientation. ${ }^{1,2}$ In this large group with head injury and a high conscious level at presentation, research has focused on developing decision rules to identify patients who require computed tomography (CT) imaging due to their risk for life-threatening TBI.

In the United Kingdom (UK), National Institute for Health and Care Excellence (NICE) and Scottish Intercollegiate Guidelines

\footnotetext{
${ }^{1,4}$ Hull York Medical School, University of Hull, Hull, United Kingdom.

${ }^{2}$ School of Health and Related Research, University of Sheffield, Sheffield, United Kingdom.

${ }^{3}$ Emergency Department, Hull and East Yorkshire NHS Trust, Hull, United Kingdom.

${ }^{5}$ Emergency Unit, Presidio Ospedaliero Morgagni-Pierantoni, AUSL della Romagna, Forlì, Italy.

${ }^{6}$ Department of Health Sciences, University of York, Alcuin Research Resource Center, Heslington, York, United Kingdom.
}

(c) Carl Marincowitz et al., 2018; Published by Mary Ann Liebert, Inc. This Open Access article is distributed under the terms of the Creative Commons License (http://creativecommons.org/licenses/by/4.0), which permits unrestricted use, distribution, and reproduction in any medium, provided the original work is properly credited. 
Network (SIGN) guidelines are used for this risk assessment, based on the Canadian CT head Rule (CCHR). ${ }^{1,3,4}$ Only $1 \%$ of head-injured patients have life-threatening TBI. ${ }^{1,4}$ However, $7 \%$ have TBI identified by CT imaging. 5

Most TBI patients who require neurosurgical intervention are identified soon after presentation. The optimal management of the remaining patients in this group remains controversial. A proportion will deteriorate due to the progression of their injuries, and so some studies advocate admission to higher dependency levels of care and repeat CT imaging. ${ }^{6,7}$

Other studies report that some low-risk patients may be safely discharged after a short period of observation in the ED. ${ }^{8,9}$ Perel and colleagues have previously outlined how prognostic models can aid clinical decision-making in TBI. ${ }^{10}$ Subsequent prognostic models, including the IMPACT, TARN, and CRASH models, have been useful in predicting adverse outcomes in patients with more severe TBI, but they are not applicable to this patient group. ${ }^{11-13}$ Equivalent prognostic models for GCS13-15 patients with CTidentified TBI may help safely reduce hospital admissions.

This review is the first to give an overview of the risk for adverse outcomes and prognostic factors in patients with mild TBI (a high or normal conscious level with traumatically induced brain dysfunction) and injuries identified by CT brain scan. The review specifically:

(i) Estimates the overall risk for adverse outcomes in patients who are initially GCS13-15 in the ED when TBI is identified by CT imaging.

(ii) Assesses which prognostic factors affect the risk for deterioration and other clinically important outcomes in this population.

\section{Methods}

A systematic review was conducted using the PRISMA P protocol and is reported in accordance with PRISMA guidelines. ${ }^{14}$ The review is registered with the PROSPERO prospective register of systematic reviews and (protocol is available at http://www.crd.york.ac.uk/ PROSPERO/display_record.asp?ID=CRD42016051585).

\section{Inclusion criteria}

Participants. Criteria were patients aged $\geq 12$ years with an initial GCS of $13-15$ with TBI identified by CT imaging. TBI included any traumatic extra-dural hemorrhage, subdural hemorrhage, intra-cerebral hemorrhage, subarachnoid hemorrhage, cerebral contusion, or skull fracture. Studies had to be conducted in the context of an emergency hospital attendance including a presentation to the ED or during admission to an inpatient ward.

Prognostic factors. Factors potentially affecting the risk for adverse outcomes were included in the analysis if they were patient factors present at admission including: demographic characteristics, co-morbidities, medication use, symptoms, other clinical features, or factors available from initial investigations.

Outcome measures. Primary outcomes were: death, neurosurgical intervention, or any other measure of clinical deterioration such that admission to a hospital was warranted. Secondary outcome was: progression of TBI on repeat CT imaging.

Types of study design. All studies, other than case studies, were included.

\section{Search methods for study identification}

Studies published before 1996 were excluded due to more liberal use of CT imaging to diagnose TBI after this date. ${ }^{5}$
The following electronic databases were searched with results restricted to English language studies:

- EMBASE (via OVID) searched 11/24/2016: 1996 to 2016, week 47;

- MEDLINE (R) (via OVID) searched 11/24/2016: 1996 to November, week 3, 2016;

- CINHAL plus (via EBSCO) searched 11/24/2016: 1983 to 2016;

- Cochrane Central Register of Controlled Trials (CENTRAL); The Cochrane Library,2016, all available dates. Accessed 11/ 24/2016.

The full search strategy is reported in Supplementary Table 1 (see online supplementary material at http://www.liebertpub.com).

The reference and citation searches of several national guidelines, reports, and reviews included: NICE, SIGN, and Australian New South Wales (NSW) guidelines; National Institute for Health Research (NIHR) Health Technology Assessment of management strategies for minor head injury; the results of the World Health Organization (WHO) collaboration on prognosis in mild TBI; systematic reviews assessing prognostic factors in TBI; and systematic reviews assessing the utility of repeat CT imaging in minor head injury. ${ }^{1,3,10,15-20}$ All included studies' references and citations were searched.

The Trauma Audit and Research Network (TARN)-listed publications were searched via the TARN website (https://www.tarn .ac.uk/Content.aspx?ca=9\&c=70; accessed 3/10/2017).

\section{Data management and extraction}

Identified studies were stored in EndNote X8 and duplicates removed.

Study selection. Two reviewers (CM and $\mathrm{AB})$ independently completed title and abstract screening. Full reports of any studies that potentially met the inclusion were selected and assessed. These were screened, and studies that did not meet the inclusion criteria were discarded with documented reasons. Disagreements were resolved through discussion or arbitration by a third reviewer (TS).

Data extraction. The following data were extracted using a prepiloted data extraction tool: study population and demographics, sample size, outcomes assessed, prognostic factors assessed, whether univariable or multi-variable modeling had been undertaken, and the overall results of the study. The selection criteria of studies were recorded to assess whether sub-populations with different risk profiles had been studied. The data extracted are presented in Supplementary Table 2 (see online supplementary material at http://www.liebertpub.com).

Assessment of the risk of bias. The Quality in Prognostic Studies (QUIPS) tool was used to assess the quality of included studies, particularly for the risk of bias. ${ }^{21}$ Six domains were assessed: study participation, study attrition, prognostic factor measurement, outcome measurement, study confounding, and statistical analysis and reporting.

\section{Statistical analysis}

Three forms of analysis were undertaken: pooling of adverse outcomes reported in studies, identification of risk factors by exploration of between-study variation in outcomes by study characteristics, and a synthesis of common risk factors assessed within studies.

A pooled prevalence of the adverse outcomes of interest and confidence intervals for individual studies were estimated using the Metaprop function (STATA-SE 14). ${ }^{22}$ The Freeman-Tukey double arscine transformation was used to include studies with no adverse outcomes, and a random effects model was used due to study heterogeneity. ${ }^{23}$ 
Between-study heterogeneity estimates of outcomes were explored using subgroup analysis. Meta-regression of study characteristics was used to identify factors that affected the risk for the outcomes of interest. Meta-regression of multiple study characteristics' effect on the prevalence of adverse outcomes was assessed using the Metareg function (STATA-SE 14) with weighting incorporating a measure of between-study variation (tau2). ${ }^{24,25}$ The $\log$ odds of clinical deterioration, neurosurgical intervention, and death were assessed as dependent variables and the standard error of the log odds was used to approximate the within-study standard error. To account for studies with no outcomes, 0.5 was added to both the outcome estimates and the sample size (consequently, in graphic representations of the metaregression the estimated risk can only tend toward zero).

Where studies had assessed the effect of risk factors on the outcomes of interest using individual data, analysis was categorized as uni-variable or multi-variable. Uni-variable meta-analysis of prognostic factor effect estimates reported in primary studies was completed using Review Manager 5.3 where possible. ${ }^{26}$ A random effects model was used due to the heterogeneity of study populations, prognostic factor, and outcome measures. ${ }^{23}$ Meta-analysis of multi-variable models was not possible due to limited numbers and variation in outcome and prognostic factor measurement.

\section{Results}

\section{Search result}

The electronic search strategy was completed on November 24,2016, and identified 4665 studies. Of these, 412 were duplicates, leaving 4253 studies for title and abstract screening (Fig. 1). Following title and abstract screening, 69 studies ${ }^{6,9,27-93}$ and two reviews ${ }^{19,20}$ were retrieved. A "gray" literature search identified a further 129 studies for title and abstract screening, of which three were retrieved. ${ }^{94-96}$

Reference and citation searching of included studies and selected reviews and guidelines identified another 46 studies, ${ }^{7,8,39,97-139}$ for full retrieval and three additional systematic reviews ${ }^{17,18,140}$ for reference and citation searches.

In total, 118 primary studies and five systematic reviews were retrieved.

Study selection. Forty-nine primary studies met the inclusion criteria. $6-9,27,28,30,32,37,41,42,52,54,55,57,59,60,62,63,65,66,69,71,73-78,86,87,90,93$, 97-104,106-109,114,125,130,139 One review presented new study data. ${ }^{18}$ The four remaining reviews formed part of the narrative synthesis. ${ }^{17,19,20,140}$ The reasons for excluding the remaining 69 studies are presented in Supplementary Table 3 (see online supplementary material at http:// www.liebertpub.com). Anonymized individual patient data were provided by the authors of a cohort study to allow outcomes for initial GCS13-15 patients to be calculated, so this study is included. ${ }^{139}$

Study characteristics. Supplementary Table 4 presents the characteristics of included studies (see online supplementary material at http://www.liebertpub.com). Seven prospective studies were identified ${ }^{28,66,74,75,90,114,139}$ and four studies had a sample size of over $1000 .^{63,87,98,108}$ Forty-six studies estimated the outcomes of interest and contributed to pooled estimates of risk. ${ }^{6-9,27,28,30,32,37,41,42,52 \text {, }}$ $54,55,57,59,60,62,63,65,66,69,71,73-78,86,87,90,93,97-104,106-109,114,125,130,139$ Four studies presented data regarding specific injury subtypes. ${ }^{32,55,71,103}$

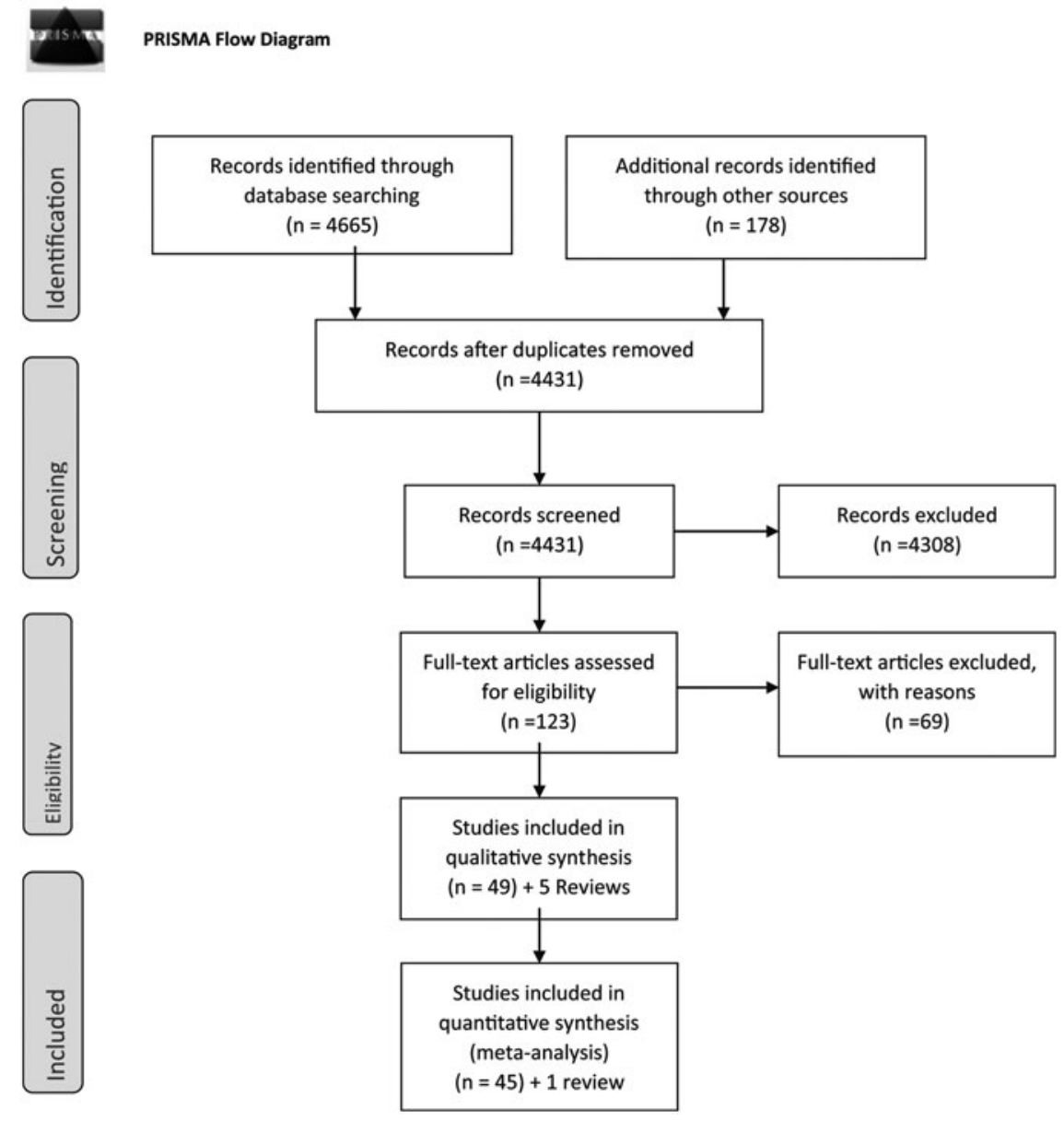

FIG. 1. PRISMA flow-diagram showing selection of studies for inclusion in the systematic review. 
One study only contributed to the narrative synthesis due to the outcome measure it assessed. ${ }^{42}$ Three studies presented the Brain Injury Guidelines (BIG) risk stratification tool. ${ }^{9,27,109}$ As this tool was applied to all TBI patients and initial GCS forms part of risk stratification, these studies contributed to the narrative synthesis.

Twenty-one studies presented either uni-variate or multivariable analysis assessing prognostic factors' effect on the outcomes of interest. $6,37,41,54,55,66,69,71,73-78,87,98-101,130,139$ Sixteen studies presented multi-variable models using logistic regression or recursive partitioning. ${ }^{6,37,41,54,55,66,69,71,73,74,77,78,98,100,101,130}$ Only two studies attempted to validate such models by splitting the study datasets. $^{66,98}$

Quality assessment. QUIPS quality scores are presented in Supplementary Table $2 .^{21}$ The following common methodological issues were identified.

Study recruitment was often not representative of all GCS 13-15 patients with TBI identified by CT imaging. Sixteen studies that contributed to the pooled estimates of adverse outcomes only included patients who had undergone repeat CT imaging, and so are likely to represent a higher-risk population. $7,18,54,74-78,86,90,102,104,106,107,125,130$ Even when re-imaging was presented as routine practice, it was often indicated that not all patients were re-imaged and included in analysis. ${ }^{6}$ Many other studies excluded higher-risk anti-coagulated patients or those with more severe injuries.

Prognostic factor measurement was not consistent. Continuous variables were dichotomized at different thresholds or the same risk factor was measured with different methods. For example, the severity of injury identified by CT imaging was assessed with 10 different measures. Most studies were retrospective and reliant on the accuracy of case notes and radiological reports. The small sample size of many studies prevented multi-variable modeling with all variables identified in uni-variable modeling as affecting deterioration. ${ }^{37}$

In 32 studies, outcomes were assessed during inpatient admission, and so patients who were discharged and deteriorated were missed. In other studies, is wasn't clear when outcome measures were assessed. Eight different measures of clinical deterioration were used in 18 studies.

Several studies included patients with extra-cranial injuries and significant co-morbidities. Extra-cranial injuries caused clinical interventions, and in studies that measured deterioration in this way this was a potential source of bias. ${ }^{66}$ Other studies indicated some recorded deaths were related to co-morbidities instead of TBI. ${ }^{41,73}$

\section{Risk of adverse outcomes and exploration of between-study variation}

Death. Twenty-seven studies assessed the outcome of death. $6,8,28,41,52,57,60,62,63,65,69,73-75,78,86,93,97,99-102,104,114,125,130,139$ The estimated risk of death for these studies ranged between $0-6 \%$ (median $1.1 \%$ ), and with a pooled prevalence of $1.4 \%$ (95\% confidence interval [CI]: $0.8 \%-2.2 \%$; Fig. 2). Studies that selected only initial GCS15 patients had a pooled estimate of mortality of $0.03 \%$ (95\% CI: $0 \%-0.28 \%$ ). Studies that selected populations for non-intensive care unit (non-ICU) admission or other conservative care pathways had an estimated prevalence of death of $0.1 \%$ (95\% CI: $0 \%-0.6 \%$ ).

The effect on mortality of mean GCS, average age, and selection of study population for a lower level of care was explored using meta-regression. Increased age of study population was associated with a higher risk for death (1.05, 95\% CI: 1.00-1.12; Fig. 3), whereas higher study population GCS was associated with a lower risk for death $(0.12,95 \%$ CI: $0.02-0.86$; Fig. 4$)$. The percentage of patients taking anti-coagulants in studies was not associated with the prevalence of death $(1.05,95 \%$ CI: $0.95-1.17)$, but selection for a lower level of care compared with a higher level of care was $(0.27,95$ C.I: $0.08-0.94)$. When average age of the study population and mean study GCS were assessed in a multi-variable model they remained statistically significant predictors of mortality (Table 1), with an adjusted $\mathrm{R}$ squared of $38 \%$, indicating that these two factors explained over one-third of the variation in study estimates.

Neurosurgical intervention. Thirty-six studies reported neurosurgical outcomes. ${ }^{6-9,27,30,37,52,54,57,60,62,63,65,66,73-78,86,90,93,97-102,104,106 \text {, }}$ 109,114,125,130,139 Figure 5 presents the estimates of the proportion of patients who underwent a neurosurgical procedure stratified by the GCS inclusion criteria. Reported neurosurgical intervention prevalence ranged between 0 and $26 \%$ (median $3.1 \%$ ). The high proportion requiring neurosurgical intervention reported by Beynon and associates ${ }^{93}$ may reflect the greater use of anti-coagulants or anti-platelets (33/70 participants).

The pooled estimated neurosurgical intervention risk was $3.5 \%$ (95\% CI: $2.2 \%-4.9 \%$ ). An $\mathrm{I}^{2}$ of $96.4 \%$ indicated considerable heterogeneity. Studies conducted on initial GCS 15 patients had a lower prevalence of neurosurgical intervention: $0.2 \%$ (95\% CI: $0 \%-0.5 \%$ ). Sensitivity analysis of selection of the study population for reduced care, such as discharge, a non-ICU admission or nonroutine repeat CT imaging found the pooled estimate of neurosurgical intervention in these studies to be $0.1 \%$ (95\% CI: $0 \%-0.5 \%$ ).

The of result of meta-regression using: mean study population GCS, mean study population age, anti-coagulation, and selection of study population for non-ICU admission or other reduced care pathways is shown in Figures 6-8 and Table 1. Increasing age (1.01, 95\% CI: $1.02-1.11)$ and increasing percentage of study population taking anti-coagulants $(1.1,95 \% \mathrm{CI}$ : $1.01-1.19)$ was associated with a higher risk, whereas an increasing GCS (0.71, 95\% CI:0.01-0.56) was associated with a lower risk, of neurosurgical intervention.

Figure 7 shows a cluster of four small studies with low mean ages that appear to have a disproportionately low estimated prevalence of neurosurgical intervention. ${ }^{8,52,62,106}$ This is explained by: exclusion of anti-coagulated patients, ${ }^{8,52,62}$ selection of patients for non-ICU admission or other reduced other care pathays, ${ }^{8,52,62}$ and exclusion of patients with large injuries. ${ }^{8}$

When the effect of population selection for reduced clinical management, exclusion of anti-coagulated patients (only 23/36 studies reported percentage of anti-coagulated patients), mean age, and GCS of the study population were all included in a metaregression, age and GCS were the only statistically significant predictors of neurosurgical intervention (Table 1). The adjusted $\mathrm{R}$ squared of the model was $48 \%$, indicating that these factors accounted for almost half of between-study variation.

Clinical deterioration. Eighteen studies measured prevalence of clinical deterioration. $8,37,41,63,66,69,73,74,76-78,100,101,104,107,108,114,125$ The estimated risk of deterioration ranged between 0 and $24.5 \%$ (median 12.8\%). Figure 9 presents study estimates of the percentage of patients who deteriorated, with $95 \%$ CIs and stratified by how the outcome was assessed. A pooled prevalence of $11.7 \%$ (95\% CI: $8.21 \%-5.8 \%$ ) for some form of clinical deterioration was estimated with an $\mathrm{I}^{2}$ of $95.7 \%$.

Estimates were stratified by: initial GCS of patients, whether the included population were all selected for repeat CT imaging, the 


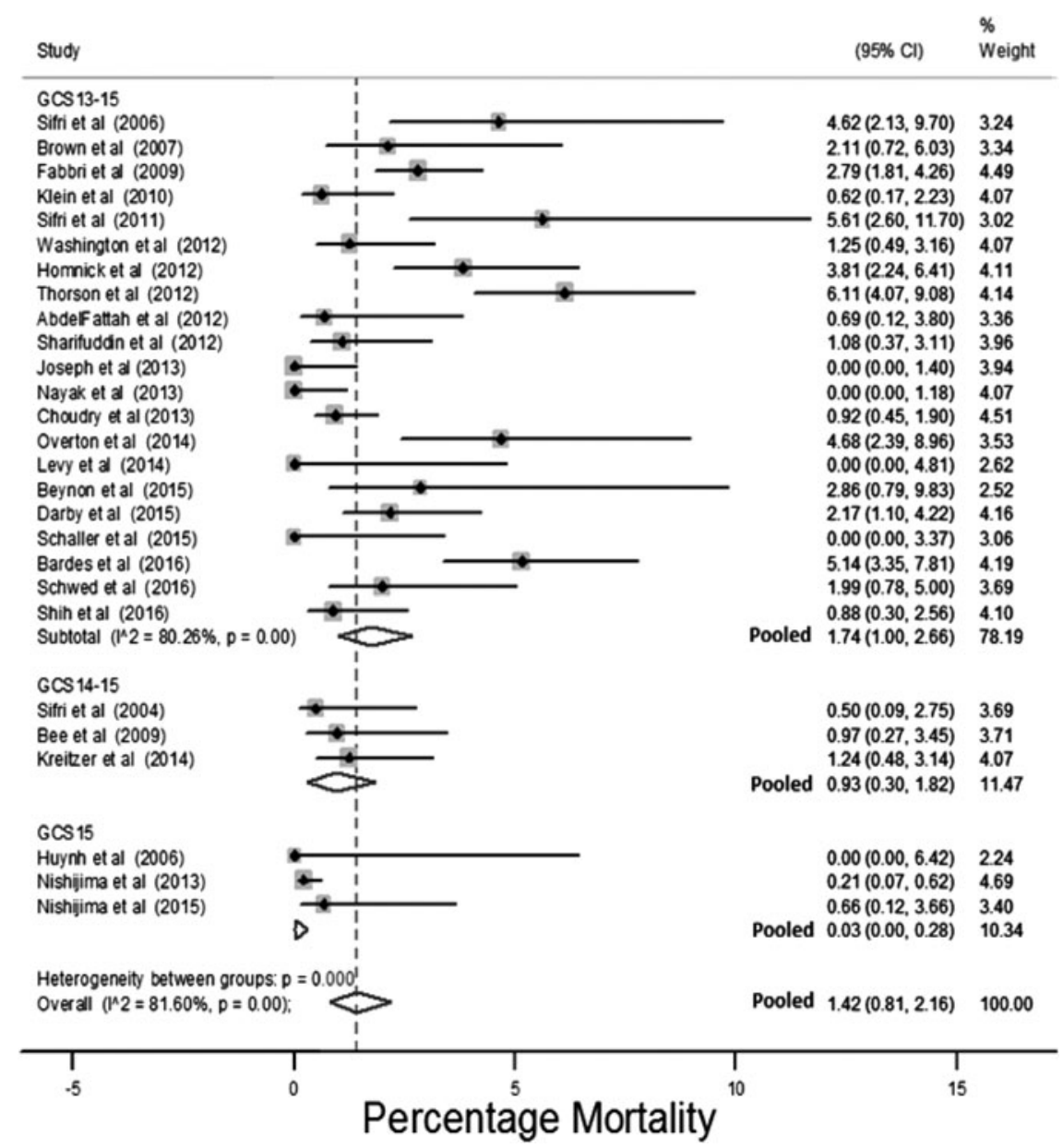

FIG. 2. Risk for death stratified by initial Glasgow Coma Scale (GCS).

inclusion of anti-coagulated patients, the follow-up period, and exclusion of patients with extra-cranial injuries. None of these factors reduced the observed between-study heterogeneity.

The effect of: mean GCS study population, mean age study population, study population selection, exclusion of patients with

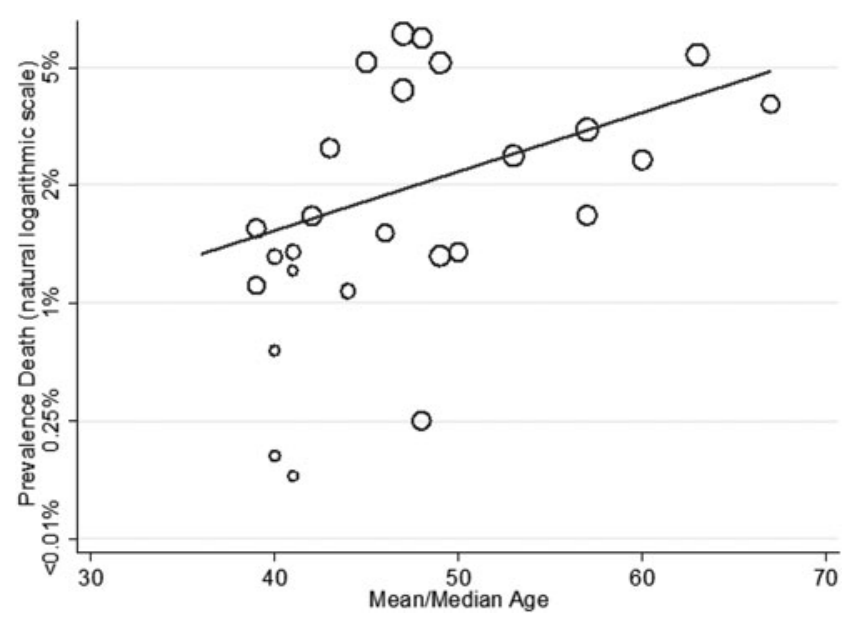

FIG. 3. Meta-regression of risk for death by mean age study population (coefficient odds $1.05,95 \%$ confidence interval [CI]: $1.00-1.12 ; p=0.049)$. extra-cranial injuries, and exclusion of anti-coagulated patients was explored using meta-regression. As only 18 studies measured this outcome, the model was restricted to two variables. No factor assessed individually or in conjunction with another factor was found to statistically affect the risk of clinical deterioration. Higher age

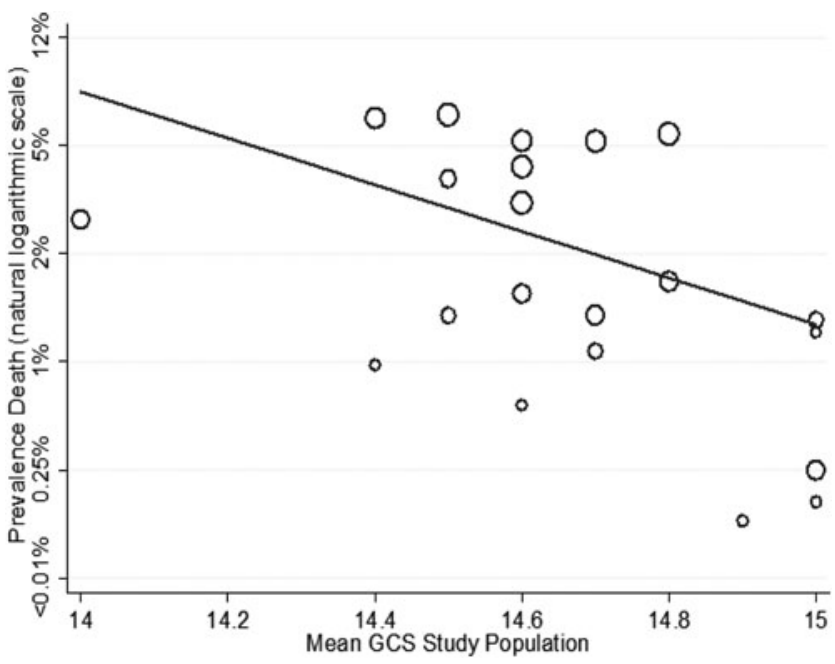

FIG. 4. Meta-regression of risk for death by mean Glasgow Coma Scale (GCS) study population (coefficient odds $0.12,95 \%$ confidence interval [CI]: 0.02-0.86; $p=0.04)$. 
Table 1. Meta-Regression of Study Factors Predictive for Death, Neurosurgery, and Clinical Deterioration

\begin{tabular}{|c|c|c|c|}
\hline Factor & Outcome & $\begin{array}{c}\text { Unit increase affect } \\
\text { odds uni-variable model }\end{array}$ & $\begin{array}{c}\text { Unit increase affect } \\
\text { odds multi-variable model }\end{array}$ \\
\hline Mean age study population & Death & 1.05 (95\% CI: $1.0003-1.12), p=0.049$ & 1.06 (95\% CI: $1.0002-1.12), p=0.049$ \\
\hline Mean GCS study population & Death & 0.12 (95\% CI: $0.02-0.86), p=0.04$ & 0.09 (95\% CI: $0.01-0.59), p=0.02$ \\
\hline $\begin{array}{l}\text { Lower-risk study population } \\
\text { vs. ICU population }\end{array}$ & Death & 0.27 (95\% CI: $0.08-0.94), p=0.04$ & \\
\hline $\begin{array}{l}\text { Unselected study population } \\
\text { vs. ICU population }\end{array}$ & Death & 0.81 (95\% CI: $0.22-1.97), p=0.63$ & \\
\hline $\begin{array}{l}\text { Percentage population } \\
\text { anti-coagulated }\end{array}$ & Death & 1.05 (95\% CI: $0.95-1.17), p=0.32$ & \\
\hline Mean age study population & Neurosurgery & 1.01 (95\% CI: $1.02-1.11), p=0.01$ & 1.09 (95\% CI: $1.02-1.16), p=0.02$ \\
\hline Mean GCS study population & Neurosurgery & $0.71(95 \%$ CI: $0.01-0.56), p=0.01$ & 0.12 (95\% CI: $0.02-0.91), p=0.04$ \\
\hline $\begin{array}{l}\text { Lower-risk study population } \\
\text { vs. ICU population }\end{array}$ & Neurosurgery & 0.13 (95\% CI: $0.04-0.41), p<0.01$ & 0.67 (95\% CI: $0.10-4.37), p=0.66$ \\
\hline $\begin{array}{l}\text { Unselected study population } \\
\text { vs. ICU population }\end{array}$ & Neurosurgery & 0.95 (95\% CI: $0.43-2.12), p=0.90$ & 1.34 (95\% CI: $0.45-4.02), p=0.58$ \\
\hline $\begin{array}{l}\text { Percentage population } \\
\text { anti-coagulated }\end{array}$ & Neurosurgery & 1.1 (95\% CI: $1.01-1.19), p=0.04$ & \\
\hline $\begin{array}{l}\text { Exclusion of anti-coagulated } \\
\text { patients in study selection }\end{array}$ & Neurosurgery & 0.63 (95\% CI: $0.27-1.43), p=0.26$ & 1.33 (95\% CI: $0.51-3.49), p=0.54$ \\
\hline Mean age study population & $\begin{array}{l}\text { Clinical } \\
\text { deterioration }\end{array}$ & 1.01 (95\% CI: $0.95-1.09), p=0.64$ & 1.02 (95\% CI: $0.93-1.12), p=0.59$ \\
\hline Mean GCS study population & $\begin{array}{l}\text { Clinical } \\
\text { deterioration }\end{array}$ & 0.36 (95\% CI: $0.04-3.20), p=0.33$ & 0.26 (95\% CI: $0.02-3.76), p=0.29$ \\
\hline
\end{tabular}

CI, confidence interval; ICU, intensive care unit; GCS, Glasgow Coma Scale.

and lower GCS were non-statistically associated with a higher risk of clinical deterioration (Table 1).

Progression on repeat CT imaging. Twenty-six studies assessed the outcome progression of the initial injury on repeat CT imaging. ${ }^{6,18,27,28,30,41,62,74-78,87,90,97,99-102,104,106-108,114,125,130}$ The prevalence of this outcome in these studies is presented in Figure 10, stratified by whether studies only included patients who had undergone repeat CT imaging. The pooled estimate for this outcome was $15.6 \%$ (95\% CI: $11.3 \%-20.4 \%$ ). There is a high degree of heterogeneity with a range in risk of progression between 2 and $48 \%$ (median $36.5 \%$ ) and $\mathrm{I}^{2}=97 \%$. The non-statistically significant higher pooled risk in studies that included only patients who had undergone repeat CT imaging probably reflects selection of higher-risk patients to repeat imaging. Subgroup analysis of study characteristics did not find any factors that accounted for the heterogeneity. This is probably the result of different criteria used to triage patients to repeat $\mathrm{CT}$ imaging and definition of progression of injury.

\section{Prognostic factors assessed in primary studies}

Twenty-one studies presented within-study estimates of effect of individual risk factors on the outcomes of interest (Supplementary Table 4) and the factors assessed are presented in Supplementary Table 5 (see online supplementary material at http://www.liebertpub. com). $6,37,41,54,55,66,69,71,73-78,87,98-101,130,139$ The most influential factors were: age, initial GCS, severity of CT finding, type of injury, anticoagulation, and anti-platelet medication (Table 2). Individual forest plots are presented in Supplementary Table 6.

Age. Age was evaluated as a factor in prognostic modeling in 18 primary studies. $6,37,41,54,55,66,69,71,73,74,76-78,98-101,130$ Ten studies $^{37,41,54,66,73,74,76-78,101}$ assessed age using four different di- chotomous cutoffs and 11 studies measured age as a continuous factor. ${ }^{6,55,69,71,73,76,77,98-100,130}$ Multi-variable models included: logistic regression with age either a dichotomized or continuous variable, or decision tree analysis.

Of these 18 studies: six assessed the outcome of clinical deterioration, eight assessed the outcome of neurosurgical intervention, one measured death as an outcome, and eight studies evaluated progression of injury on repeat CT imaging. Despite being the most commonly assessed prognostic factor, due to the variation in measurement and the outcomes assessed, it was not possible to undertake a pooled analysis.

Increased age was associated with an adverse outcome in 9 of the 19 uni-variable models presented. Age was a significant predictor of an adverse outcome in 2 of 5 multi-variable models where it was treated as a continuous variable. ${ }^{69,71,98,130}$ However, in 4 of 6 multivariable models where it was dichotomized, older age predicted the outcomes of interest. ${ }^{41,54,66,73,78,101}$ This may indicate a non-linear relationship with older age groups having a disproportionately higher associated risk for adverse outcomes.

Initial GCS. Twelve primary studies presented within-study estimates of the effect of initial GCS on the risk of the outcomes of interest. $6,37,41,55,66,69,73,74,77,98,100,101$ Uni-variable effect estimates of initial GCS of 15 were pooled for studies assessing clinical deterioration and neurosurgical intervention as an outcome with individual patient data provided by Fabbri and co-workers, and an initial GCS of 15 was protective against clinical deterioration or neurosurgical intervention (pooled odds ratio [OR] 0.35, 95\% CI: 0.23-0.53; Table 2). ${ }^{37,41,66,73,74,77,101}$ Two articles assessed progression of injury on repeat $\mathrm{CT}$ imaging and both found an initial GCS of 15 to be associated with reduced risk of progression. ${ }^{74,77}$ Four studies estimated the effect of an initial GCS of 15 in multivariable models. ${ }^{37,66,73,101}$ All four multi-variable models found 


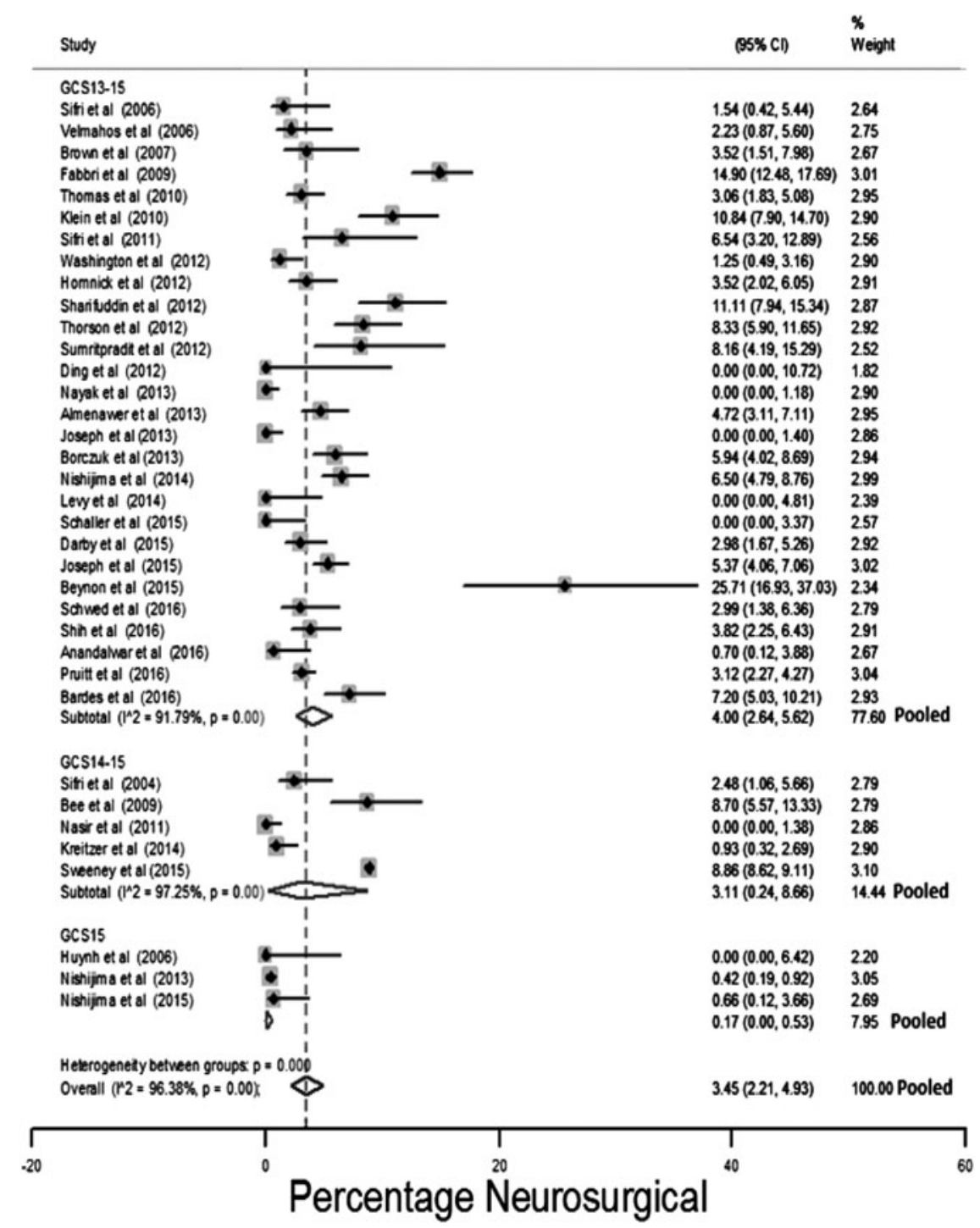

FIG. 5. Risk for neurosurgery stratified by the initial Glasgow Coma Scale (GCS) of the study population.

initial GCS of 15 to be associated with a reduced risk of adverse outcomes.

Severity of injury as assessed by CT findings. Nine studies estimated whether the severity of injury identified by initial CT scan predicted adverse outcomes. ${ }^{6,41,54,55,66,73,76,78,100}$ This was assessed by: the presence of midline shift or mass effect in five studies, ${ }^{6,55,66,76,100}$ the Marshall classification in two studies, ${ }^{41,73}$ and measures of hemorrhage thickness or volume in four studies. ${ }^{54,55,78,100}$ The variability in the measures of injury severity and differences in the outcomes assessed prevented pooling.

All studies that assessed presence of midline shift/mass effect found it to be statistically predictive of adverse outcomes. This association remained in the two studies that presented multivariable analysis. ${ }^{6,66}$ The Marshall classification was assessed as a continuous ${ }^{73}$ and dichotomized variable, ${ }^{41}$ and neither study found a statistically significant association with adverse outcomes.

The two studies that assessed the effect of bleed thickness $>10 \mathrm{~mm}$ found this to be statistically predictive of either progression of injury on repeat CT imaging or neurosurgical intervention in both uni- and multi-variable analysis. ${ }^{54,78}$

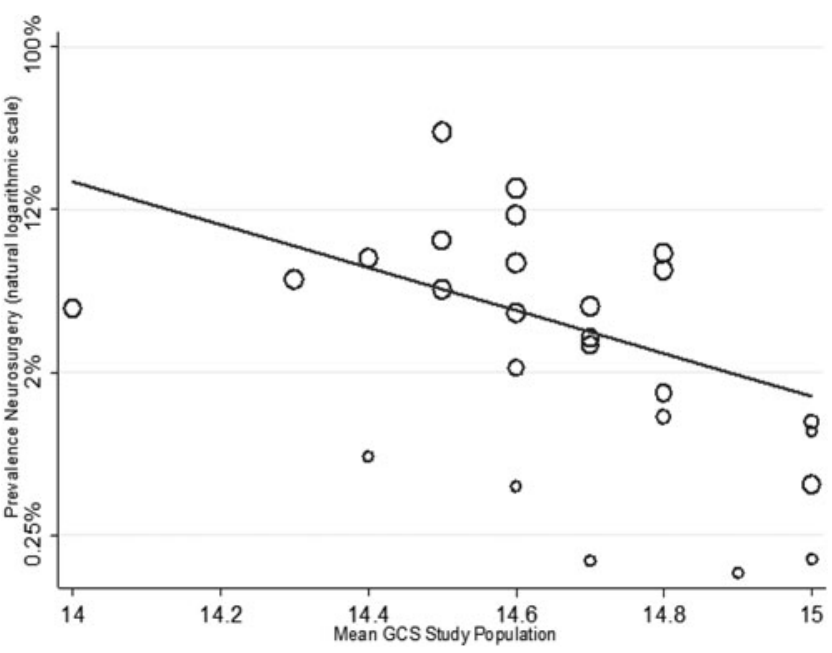

FIG. 6. Meta-regression of risk for neurosurgery by mean Glasgow Coma Scale (GCS) study population (coefficient odds $0.71,95 \%$ confidence interval $[\mathrm{CI}]: 0.01-0.56 ; p=0.01$ ). 


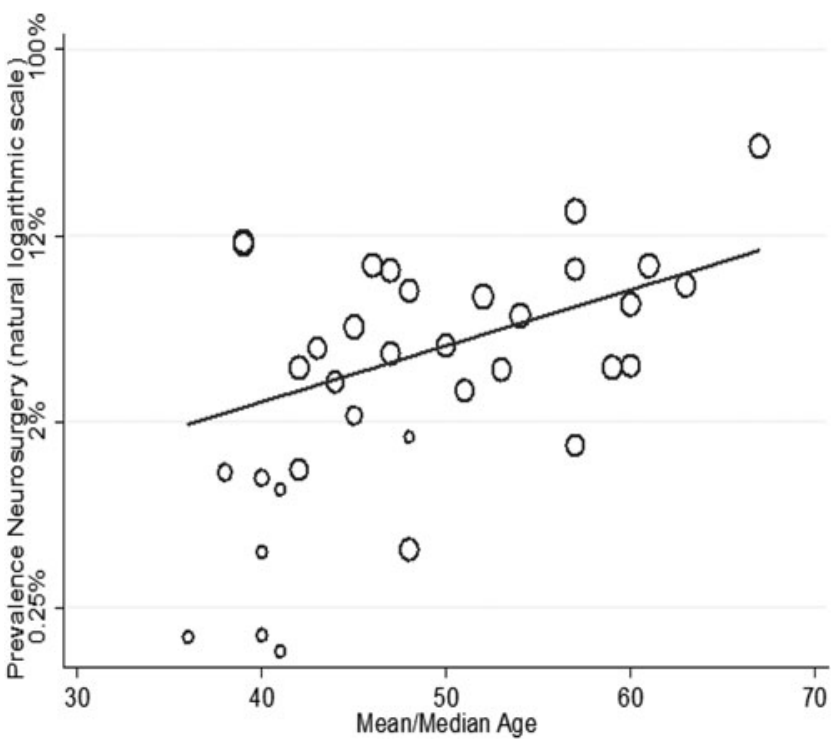

FIG. 7. Meta-regression of risk for neurosurgery by mean age study population (coefficient odds $1.01,95 \%$ confidence interval [CI]: $1.02-1.11 ; p=0.01)$.

Isolated subarachnoid hemorrhage. Twelve studies presented outcomes for populations with isolated injuries and patients with isolated subarachnoid hemorrhages (iSAH) had the lowest risk for adverse outcomes: neurosurgical intervention pooled risk $0.01 \%$ (95\% CI: $0 \%-0.7 \%$; Fig. 11 ), and $1.1 \%$ (95\% CI: $0 \%-5.5 \%$ ) pooled prevalence of clinical deterioration (Supplementary Fig. 1; (see online supplementary material at http://www.liebertpub.com). ${ }^{32,37,55,59,71,74,77,98,99,103,107,108}$

Uni-variable effect estimates presented in the two studies that assessed the effect of the presence of iSAH were pooled with data extracted from three additional studies. ${ }^{37,73,77,98,108}$ The pooled estimate indicated iSAH reduced the risk of neurosurgical intervention/clinical deterioration (Table 2).

Two multi-variable models included iSAH as a prognostic factor. One found iSAH to be associated with a lower risk for clinical deterioration. ${ }^{37}$ The other found iSAH to have no effect on risk. ${ }^{98}$

Isolated extra-dural hemorrhage. Patients with isolated extra-dural hemorrhage had the highest risk for neurosurgical in-

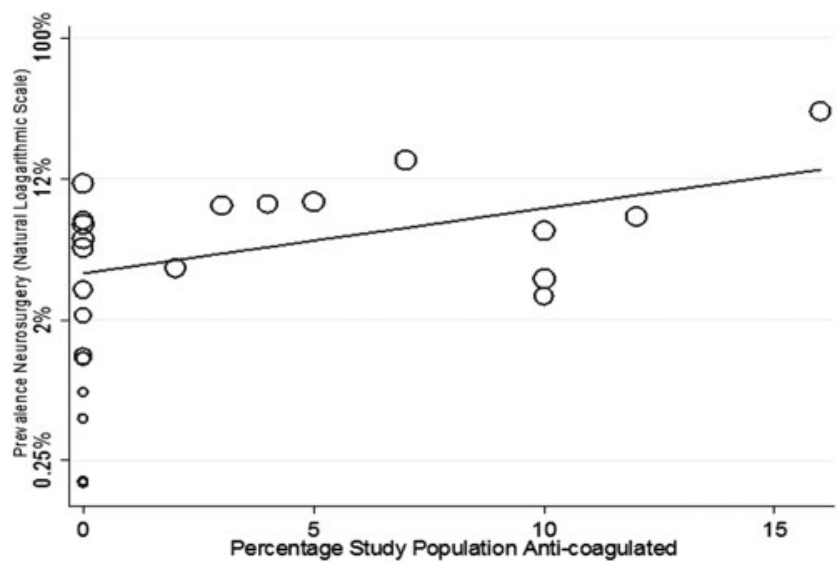

FIG. 8. Meta-regression of risk for neurosurgery by percentage of study population taking anti-coagulants (coefficient odds 1.1, 95\% confidence interval $[\mathrm{CI}]: 1.01-1.19 ; p=0.04)$. tervention: $13.7 \%$ (95\% CI: $9.3 \%-18.5 \%$; Fig. 11$)$; $18.5 \%$ is estimated from a population of all initial GCS14-15 patients with extra-dural hemorrhage, whereas the estimates in the other studies are from populations that have been selected for more conservative management. ${ }^{77,98,107,108}$

Three studies assessed isolated extra-dural hmorrhage as a prognostic factor. ${ }^{37,73,98}$ A pooled risk estimate for clinical deterioration or neurosurgical intervention using these three studies and outcome data extracted from a further two studies, ${ }^{77,108}$ found isolated extra-dural hemorrhage to be associated with these outcomes (OR 2.26, 95\% CI: 1.9-2.68; Table 2). Isolated extra-dural hemorrhage remained statistically associated with neurosurgical outcomes in the only multi-variable model that included this factor. ${ }^{98}$

Anti-coagulation. Twelve studies estimated the prognostic effect of anti-coagulation. 6,37,41,55,74,76-78,98,100,101,139 Measures of anticoagulation included: any documented coagulopathy, 6,41,55,77,98,100 pre-injury warfarin use ${ }^{37,76,101}$ warfarin or anti-platelet therapy as a combined risk factor, ${ }^{78,100}$ and continuous laboratory measures of anticoagulation. ${ }^{6,74,101}$

Uni-variable effect estimates of dichotomous measures of anticoagulation were pooled with individual patient data from Fabbri and colleagues for the composite outcome of clinical deterioration or neurosurgical intervention (Table 2), pooled estimate: OR 1.45, 95\% CI: $1.28-1.64$.

Two studies presented multi-variable models that included anticoagulation and it was not statistically associated with the outcomes of interest in either model. ${ }^{78,98}$

Anti-platelet medication. The effect of anti-platelet use was evaluated by: aspirin use, ${ }^{37,76,101}$ clopidogrel use, ${ }^{37,76,101}$ and a joint measure of anti-platelet use. ${ }^{55,66,87}$ No multi-variable models included anti-platelet use. Pooled uni-variable risk estimates of preinjury aspirin and clopidogrel use are presented in Table 2. Metaanalysis indicated a statistical association between clopidogrel and clinical deterioration or neurosurgical intervention, but there was no association between aspirin use and this outcome.

\section{Discussion}

\section{Summary}

We have completed a thorough systematic review and metaanalysis to identify risk factors for adverse outcomes in this TBI population. This is the first review to provide pooled estimates of clinically important outcomes in this population and identify which factors affect the risk for these outcomes.

The pooled prevalence for adverse outcomes was: $11.7 \%$ (95\% CI: $8.21 \%-5.8 \%$ ) clinical deterioration, $3.5 \%$ (95\% CI: $2.2 \%-4.9 \%$ ) neurosurgical intervention, and $1.4 \%$ (95\% CI: $0.8 \%-2.2 \%$ ) death. These outcome estimates used a pooled total of 65,724 patients and are comparable to the $2.7 \%$ craniotomy rate reported for a similar population in a national UK trauma database. ${ }^{94}$ The variation in individual study outcomes reflects differences in populations studied and outcome definitions. For the outcomes of neurosurgical intervention and death, heterogeneity could be explained by the age of study populations and different study population GCS scores.

Risk factors for adverse outcomes were identified using both metaregression of study characteristics and synthesis of prognostic models presented by primary studies. Age, anti-coagulation, and initial GCS were found by both methods to affect risk. An increase in mean study population age by one year was associated with increased odds of neurosurgical intervention of 1.09 in multi-variable meta-regression 


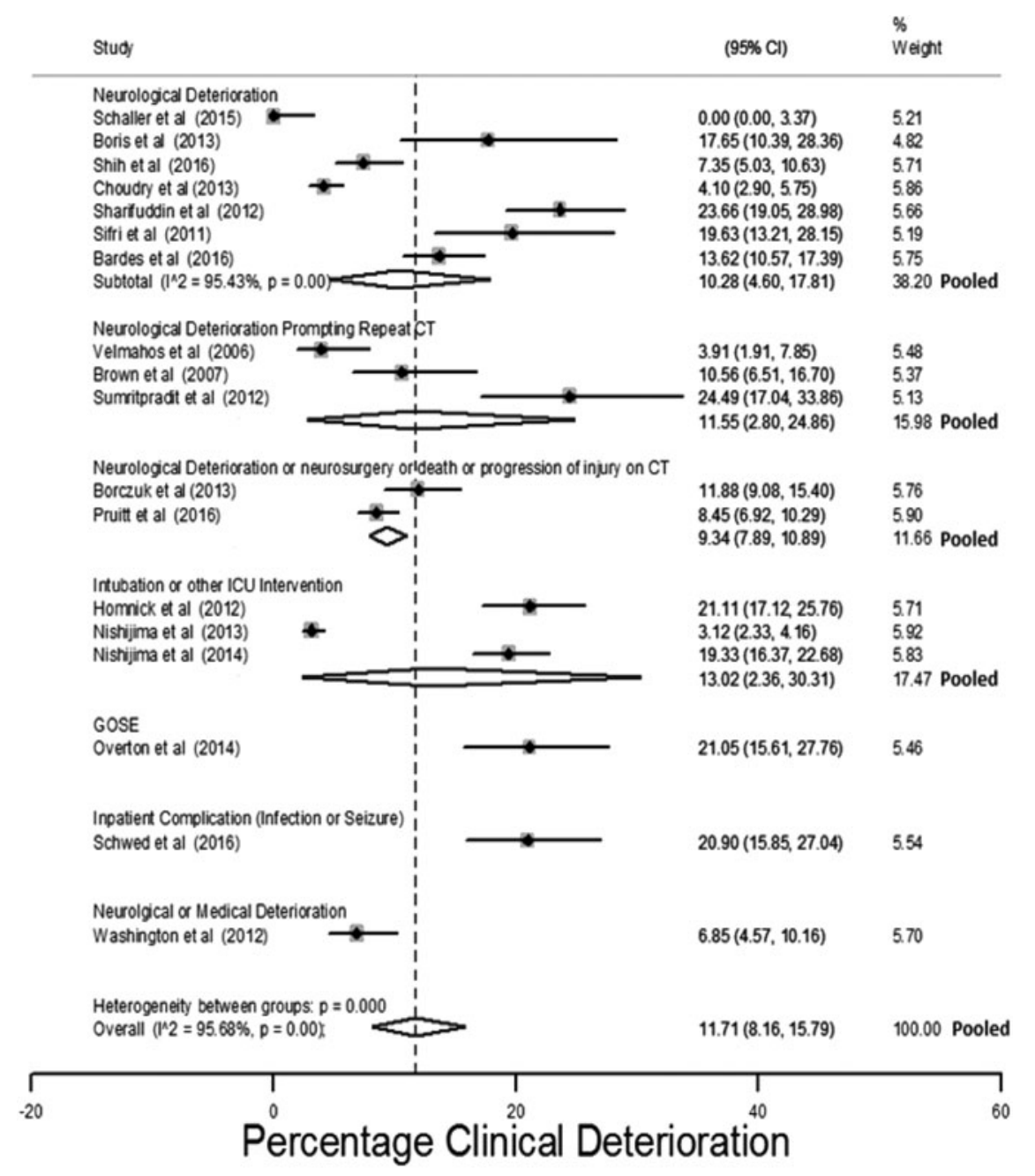

FIG. 9. Estimates of clinical deterioration stratified by the outcome measure.

(Table 1), and age was a predictor for an adverse outcome in 6 of 11 multi-variable models presented in primary studies. In uni-variable meta-regression a unit increase in the percentage of the study population taking anti-coagulants was associated with a 1.1 increase in the odds of neurosurgical intervention (Table 1). Pooling of uni-variable models presented in primary studies found anti-coagulated patients to have odds 1.45 times greater than patients not anti-coagulated for neurosurgical intervention/clinical deterioration (Table 2). In multivariable meta-regression, a unit increase in mean/median study population GCS was associated with a 0.12 reduction in the odds of neurosurgical intervention (Table 1). Pooling of uni-variable models indicated that patients with an initial GCS $<15$ had odds of clinical deterioration/neurosurgical intervention 2.9 times that of patients who presented with an initial GCS of 15 (Table 2). In multi-variable metaregression models including both initial GCS and age, initial GCS had a smaller effect on the risk for either neurosurgical intervention or death than in uni-variable analysis, and this may be due to older patients presenting with higher initial GCS relative to the severity of their injury (Table 1). ${ }^{141}$ Patients with extra-dural hemorrhage had the highest prevalence of adverse outcomes, whereas patients with iSAH had the lowest (Fig. 11).

Meta-analysis of multi-variable models was not possible due to the small number and variability in how these models were constructed. Therefore, although this review has identified the factors that affect risk, no model that could identify low-risk patients was found or could be reliably constructed.

\section{Strengths}

A thorough search has been conducted, identifying 50 relevant primary studies. Our review fulfills all the AMSTAR systematic review checklist quality domains apart from items 10 and 11, regarding the assessment of publication bias and conflicts of interest. ${ }^{142}$ However, the non-interventional nature of the included studies means these domains are less relevant. This review is low-risk for bias in the five domains assessed by the Risk of Bias in Systematic reviews (ROBIS) tool. ${ }^{143}$

\section{Limitations}

Many studies identified were small and retrospective with limited follow-up of patients after discharge. Instead of attempting to identify low-risk patients through prognostic modeling, several studies selected patients on study-specific characteristics for different care pathways. This variation in study populations contributed to heterogeneity in estimates of outcome prevalence and risk-factor effect. The prognostic models that were identified were often derived in cohorts too small to construct multi-variable models with all relevant factors. The clinically useful outcome in informing discharge decisions is clinical deterioration, and most prognostic models did not assess this. 


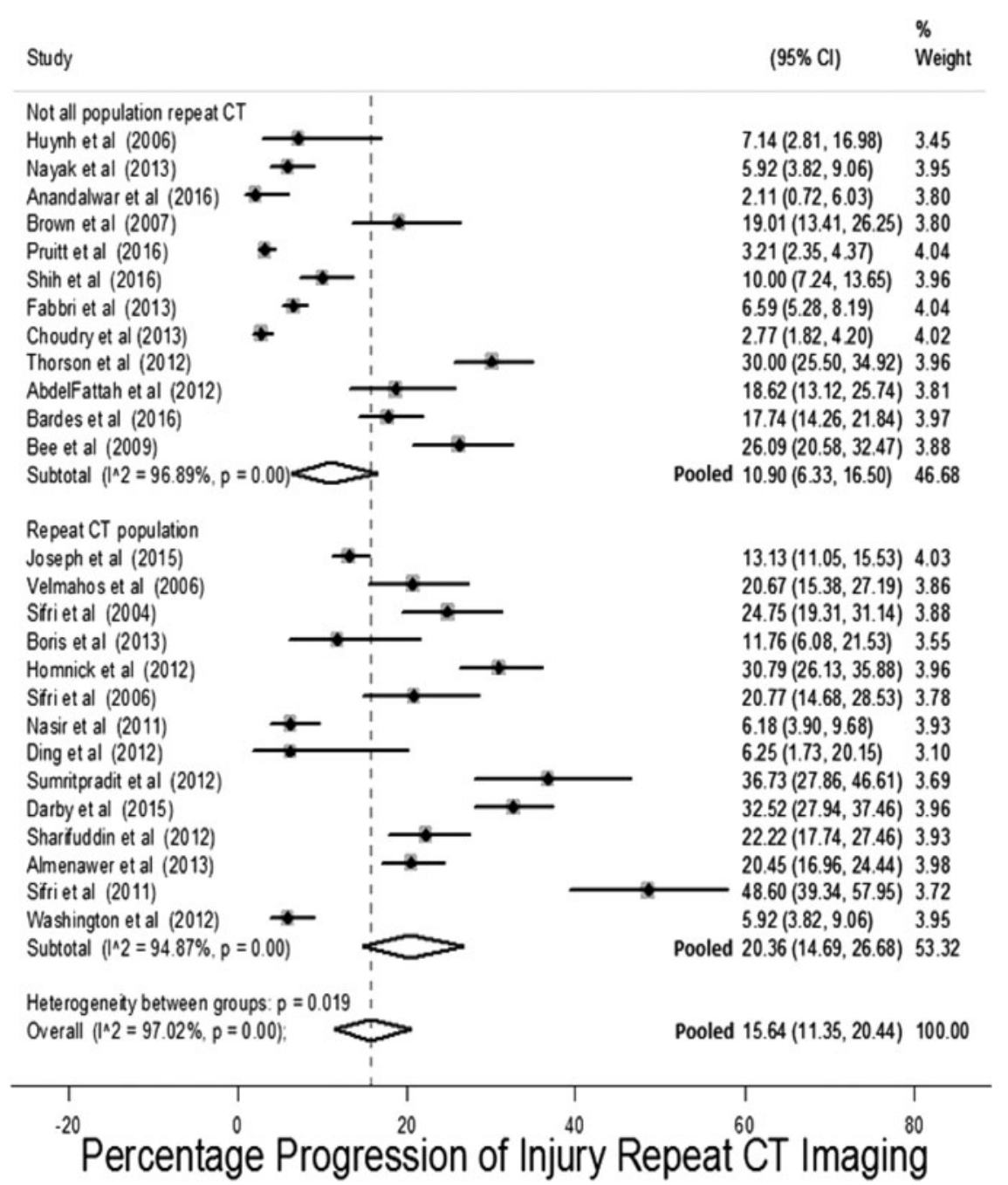

FIG. 10. Risk on repeat computed tomography (CT) imaging for progression of injury stratified by whether entire population selected for repeat imaging.

Table 2. Summary of Effect Estimates of Risk Factors Assessed within Studies

\begin{tabular}{|c|c|c|c|c|}
\hline Risk factor & Number of studies assessed in & Pooled uni-variable effect ${ }^{\mathrm{a}}$ & $\begin{array}{c}\text { Effect } \\
\text { multi-variable } \\
\text { models }^{\mathrm{b}}\end{array}$ & $\begin{array}{c}\text { Likely effect } \\
\text { on risk }\end{array}$ \\
\hline Age & $18^{6,37,41,54,55,66,69,71,73,74,76-78,98-101,130}$ & & $+6 / 11$ & + \\
\hline Initial GCS 15 & $7^{37,41,66,73,74,77,101}$ & OR $0.35,95 \%$ CI: $0.23-0.52$ & $-4 / 4$ & - \\
\hline Severity CT brain & $9^{6,41,54,55,66,73,76,78,100}$ & & $+7 / 8$ & + \\
\hline Isolated SAH & $5^{37,73,77,98,108}$ & OR $0.19,95 \%$ CI: $0.07-0.5$ & $-1 / 2$ & - \\
\hline Isolated EDH & $5^{37,73,77,98,108}$ & OR $2.26,95 \%$ CI: $1.9-2.68$ & $+1 / 1$ & + \\
\hline Isolated SDH & $5^{37,73,77,98,108}$ & OR $1.82,95 \%$ CI: $0.69-4.77$ & $+2 / 2$ & \\
\hline Isolated contusion & $3^{37,98,108}$ & OR $0.24,95 \%$ CI: $0.2-0.28$ & $0 / 1$ & \\
\hline Anti-coagulation & $12^{6,37,41,55,74,76-78,98,100,101,139}$ & OR $1.45,95 \%$ CI: $1.28-1.64$ & $0 / 2$ & + \\
\hline Aspirin & $6^{37,55,66,76,87,101}$ & OR $1.30,95 \%$ CI: $0.95-1.78$ & & \\
\hline Clopidogrel & $6^{37,55,66,76,87,101}$ & OR $1.79,95 \%$ CI: $1.17-2.72$ & & + \\
\hline
\end{tabular}

${ }^{\mathrm{a}}$ Pooled estimate of effect on risk of neurosurgery or clinical deterioration.

bindicates number of multi-variable models where factor was found to be a significant predictor and direction of effect on risk.

CI, confidence interval; CT, computed tomography; EDH, extra-dural hemorrhage; GCS, Glasgow Coma Scale; OR, odds ratio; SAH, subarachnoid hemorrhage. 


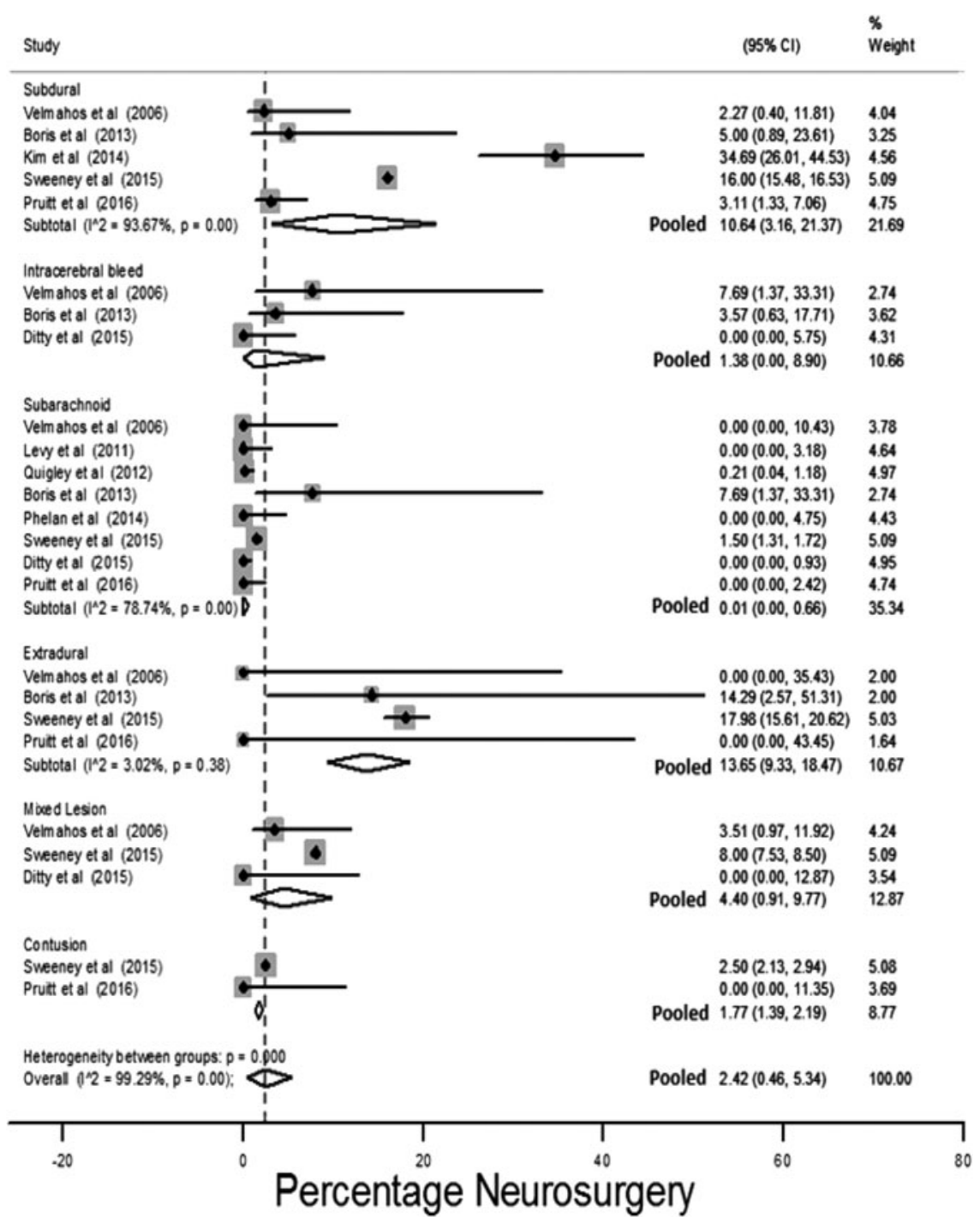

FIG. 11. Pooled risk for neurosurgery stratified by isolated injury type identified by initial computed tomography (CT) imaging.

Clinical deterioration was defined by seven different composite outcomes and most commonly by neurological deterioration. This lack of consistency in definition contributed to the heterogeneity in outcome estimates. Neurological deterioration was variably defined and a clinically relevant and consistently used definition or deterioration is required.

No included studies assessed pupillary response and duration of loss of consciousness/amnesia. These factors are predictive for adverse outcomes in other TBI populations and future research should assess these factors in this population. ${ }^{13,144}$

\section{Context}

When the Canadian CT Head Rule was developed, the authors presented a consensus-derived list of intra-cranial injuries that would never require neurosurgical intervention. ${ }^{4}$ The implication was that patients with such injuries were safe for discharge. This was rejected by the Society of British Neurological Surgeons. ${ }^{1}$ A U.S. group based in Arizona has produced the BIG consensusderived statement that identifies a population with low-risk clinical characteristics and intra-cranial injuries similar to those presented by the CCHR authors. ${ }^{109}$ They propose such patients are safe for discharge after $6 \mathrm{~h}$ of ED observation. ${ }^{9,27,109}$

Kreitzer and associates present an alternative policy at a level 1 trauma center in Cincinnati, where the population of interest remains in the ED for observation and undergoes repeat CT imaging approximately $6 \mathrm{~h}$ following diagnosis. ${ }^{86}$ Neurologically stable patients without progression of injury are discharged. Pruitt and co-workers present a model of care in a level 1 trauma center in Chicago in which all GCS13-15 patients with intra-cranial injuries receive a neurosurgical consultation. ${ }^{108}$ Low-risk patients identified by the neurosurgeon are left under ED care and discharged after a period of observation. This is similar to the standard of care in the UK National Health Service (NHS).

Others advocate the admission of GCS13-15 patients with brain injuries identified by CT imaging to higher levels of care and routine re-imaging, citing evidence that deterioration in neurological examination may not identify progression of injury that warrants clinical intervention. ${ }^{6,78}$ Multiple reviews have found that this is too rare an occurrence to warrant routine re-imaging of all GCS13-15 patients with TBI identified by CT. ${ }^{17-20}$ 


\section{Implications}

This review supports the view that there are subsets of GCS13-15 patients with injuries identified by CT imaging who may possibly be safely routinely discharged from the ED. However, the current available evidence is insufficient to reliably identify such low-risk patients. The risks for serious adverse outcomes are sufficiently high that, in the absence of evidence to be able to accurately pinpoint low-risk individual patients, admission for observation probably remains clinically indicated.

No validated model predicting a measure of clinical deterioration that could be used to triage hospital admission was identified. We suggest future research should assess a measure of clinical deterioration that encompasses: neurosurgical intervention, death, a fall in GCS by 2 or more points, seizure activity, intravenous medical intervention, or ICU intervention. These would warrant ongoing inpatient hospital admission.

The BIG criteria, although the best effort at risk stratifying this group in a clinically relevant way, require validation in larger prospective cohorts in different health care contexts before being more widely adopted. They were derived by consensus, and empirical prognostic modeling could possibly improve the accuracy of risk stratification.

Decision rules have been employed successfully in the ED to risk-stratify patients in a range of conditions, including ankle injuries and suspected pulmonary embolus. ${ }^{145,146}$ Equivalent models could be used for patients with mild TBI to identify low-risk patients. This review has identified the key factors that are likely to inform such risk stratification, but an adequately powered derivation study with a clinically relevant definition of deterioration and adequate follow-up is required.

\section{Conclusion}

Mild TBI patients with injuries identified by CT imaging are a heterogenous group. Their overall risk for clinical deterioration and more serious adverse outcomes is small, but clinically significant. Current research gives an indication to which factors affect the risk for adverse outcomes but is of too low quality to inform clinical decision-making. High-quality prognostic modeling is needed to help inform discharge decisions.

\section{Acknowledgments}

Carl Marincowitz is funded by a National Institute for Health Research Doctoral Fellowship. This study presents independent research funded by the National Institute for Health Research (NIHR). The views expressed are those of the author(s) and not necessarily those of the NHS, the NIHR, or the Department of Health.

\section{Author Disclosure Statement}

No competing financial interests exist.

\section{References}

1. NICE. (2014). National Clinical Guidance Centre. (2014). CG 176 Head Injury Triage, assessment, investigation and early management of head injury in children, young people and adults. National Institute for Health and Care Excellence. NICE (ed). DOH: UK.

2. Centers for Disease Control and Prevention. (2015). Report to Congress on Traumatic Brain Injury in the United States: Epidemiology and Rehabilitation. National Center for Injury Prevention and Control; Division of Unintentional Injury Prevention. Atlanta, GA.

3. Scottish Intercollegiate Guidelines Network: Guideline 110. The Early Management of Patients with a Head Injury. Available at: www.sign.ac .uk/guidelines/fulltext/50/index.html (last accessed November 24, 2016).
4. Stiell, I.G., Wells, G.A., Vandemheen, K., Clement, C., Lesiuk, H., Laupacis, A., McKnight, R.D., Verbeek, R., Brison, R., Cass, D., Eisenhauer, M.E., Greenberg, G., and Worthington, J. (2001). The Canadian CT Head Rule for patients with minor head injury. Lancet 357, 1391-1396.

5. Haydel, M.J., Preston, C.A., Mills, T.J., Luber, S., Blaudeau, E., and DeBlieux, P.M. (2000). Indications for computed tomography in patients with minor head injury. N. Engl. J. Med. 343, 100-105.

6. Thorson, C.M., Van Haren, R.M., Otero, C.A., Guarch, G.A., Curia, E., Barrera, J.M., Busko, A.M., Namias, N., Bullock, M.R., Livingstone, A.S., and Proctor, K.G. (2013). Repeat head computed tomography after minimal brain injury identifies the need for craniotomy in the absence of neurologic change. J. Trauma Acute Care Surg. 74, 967-975.

7. Thomas, B.W., Mejia, V.A., Maxwell, R.A., Dart, B.W., Smith, P.W., Gallagher, M.R., Claar, S.C., Greer, S.H., and Barker, D.E. (2010). Scheduled repeat CT scanning for traumatic brain injury remains important in assessing head injury progression. J. Am. Coll. Surg. 210, 824-830, 831-822.

8. Schaller, B., Evangelopoulos, D.S., Muller, C., Martinolli, L., Pouljadoff, M.P., Zimmermann, H., and Exadaktylos, A.K. (2010). Do we really need 24-h observation for patients with minimal brain injury and small intracranial bleeding? The Bernese Trauma Unit Protocol. Emerg. Med. J. 27, 537-539.

9. Joseph, B., Aziz, H., Pandit, V., Kulvatunyou, N., Sadoun, M., Tang, A., O'Keeffe, T., Gries, L., Green, D.J., Friese, R.S., Lemole Jr, M.G. and Rhee, P. (2014). Prospective validation of the brain injury guidelines: managing traumatic brain injury without neurosurgical consultation. J. Trauma Acute Care Surg. 77, 984-988.

10. Perel, P., Edwards, P., Wentz, R., and Roberts, I. (2006). Systematic review of prognostic models in traumatic brain injury. BMC Med. Inform. Decis. Mak. 6, 38.

11. Roozenbeek, B., Lingsma, H.F., Lecky, F.E., Lu, J., Weir, J., Butcher, I., McHugh, G.S., Murray, G.D., Perel, P., Maas, A.I., and Steyerberg, E.W. (2012). Prediction of outcome after moderate and severe traumatic brain injury: external validation of the International Mission on Prognosis and Analysis of Clinical Trials (IMPACT) and Corticoid Randomisation after Significant Head injury (CRASH) prognostic models. Crit. Care Med. 40, 1609-1617.

12. Steyerberg, E.W., Mushkudiani, N., Perel, P., Butcher, I., Lu, J., McHugh, G.S., Murray, G.D., Marmarou, A., Roberts, I., Habbema, J.D.F., and Maas, A.I.R. (2008). Predicting outcome after traumatic brain injury: development and international validation of prognostic scores based on admission characteristics. PLoS Med. 5, 1251-1261.

13. Lesko, M.M., Jenks, T., Perel, P., O'Brien, S., Childs, C., Bouamra, O., and Lecky, F. (2013). Models of mortality probability in severe traumatic brain injury: results of the modelling by the UK trauma registry. J. Neurotrauma 30, 2021-2030.

14. Moher, D., Shamseer, L., Clarke, M., Ghersi, D., Liberati, A., Petticrew, M., Shekelle, P., and Stewart, L.A. (2015). Preferred Reporting Items for Systematic Review and Meta-Analysis Protocols (PRISMA-P) 2015 statement. Syst. Rev. 4, 1.

15. Ministry of Health, NSW. Policy Directive. Closed Head Injury in Adults - Initial Management. Available at: http://www0.health.nsw. gov.au/policies/pd/2012/pdf/PD2012_013.pdf (last accessed November 24,2016$)$.

16. Silverberg, N.D., Gardner, A.J., Brubacher, J.R., Panenka, W.J., Li, J.J., and Iverson, G.L. (2014). Systematic review of multivariable prognostic models for mild traumatic brain injury. J. Neurotrauma 32, 517-526.

17. Wang, M.C., Linnau, K.F., Tirschwell, D.L., and Hollingworth, W. (2006). Utility of repeat head computed tomography after blunt head trauma: a systematic review. J. Trauma 61, 226-233.

18. Almenawer, S.A., Bogza, I., Yarascavitch, B., Sne, N., Farrokhyar, F., Murty, N., and Reddy, K. (2013). The value of scheduled repeat cranial computed tomography after mild head injury: single-center series and meta-analysis. Neurosurgery 72, 56-62; discussion 63-54.

19. Stippler, M., Smith, C., McLean, A.R., Carlson, A., Morley, S., MurrayKrezan, C., Kraynik, J., and Kennedy, G. (2012). Utility of routine follow-up head CT scanning after mild traumatic brain injury: A systematic review of the literature. Emerg. Med. J. 29, 528-532.

20. Reljic, T., Mahony, H., Djulbegovic, B., Etchason, J., Paxton, H., Flores, M., and Kumar, A. (2014). Value of repeat head computed tomography after traumatic brain injury: systematic review and metaanalysis. J. Neurotrauma 31, 78-98.

21. Hayden, J.A., van der Windt, D.A., Cartwright, J.L., Cote, P., and Bombardier, C. (2013). Assessing bias in studies of prognostic factors. Ann. Intern. Med. 158, 280-286. 
22. Nyaga, V.N., Arbyn, M., and Aerts, M. (2014). Metaprop: a Stata command to perform meta-analysis of binomial data. Arch. Public Health 72,39 .

23. DerSimonian, R., and Kacker, R. (2007). Random-effects model for meta-analysis of clinical trials: an update. Contemp. Clin. Trials 28, $105-114$.

24. Higgins, J.P.T., and Harbord, R.M. (2008). Meta-regression in Stata. Stata J. 8, 493-519.

25. Baker, W.L., White, C.M., Cappelleri, J.C., Kluger, J., Coleman, C.I., and Health Outcomes, Policy, and Economics (HOPE) Collaborative Group. (2009). Understanding heterogeneity in meta-analysis: the role of meta-regression. Int. J. Clin. Pract. 63, 1426-1434.

26. Review Manager (RevMan) [Computer program]. (2014). Version 5.3. The Nordic Cochrane Center, T.C.C.: Copenhagen.

27. Joseph, B., Pandit, V., Haider, A.A., Kulvatunyou, N., Zangbar, B., Tang, A., Aziz, H., Vercruysse, G., O'Keeffe, T., Freise, R.S., and Rhee, P. (2015). Improving hospital quality and costs in nonoperative traumatic brain injury: the role of acute care surgeons. JAMA Surg. 150, 866-872.

28. AbdelFattah, K.R., Eastman, A.L., Aldy, K.N., Wolf, S.E., Minei, J.P., Scott, W.W., Madden, C.J., Rickert, K.L., and Phelan, H.A. (2012). A prospective evaluation of the use of routine repeat cranial CT scans in patients with intracranial hemorrhage and GCS score of 13 to 15. J. Trauma Acute Care Surg. 73, 685-688.

29. Alahmadi, H., Vachhrajani, S., and Cusimano, M.D. (2010). The natural history of brain contusion: an analysis of radiological and clinical progression. J. Neurosurg. 112, 1139-1145.

30. Anandalwar, S.P., Mau, C.Y., Gordhan, C.G., Majmundar, N., Meleis, A., Prestigiacomo, C.J., and Sifri, Z.C. (2016). Eliminating unnecessary routine head CT scanning in neurologically intact mild traumatic brain injury patients: implementation and evaluation of a new protocol. J. Neurosurg. 125, 667-673.

31. Anonymous. (2013). Erratum: Prognosis analysis and risk factors related to progressive intracranial haemorrhage in patients with acute traumatic brain injury (Brain Inj. [2012] 26:9 [1136-1142]). Brain Inj. 27, 251.

32. Ditty, B.J., Omar, N.B., Foreman, P.M., Patel, D.M., Pritchard, P.R., and Okor, M.O. (2015). The nonsurgical nature of patients with subarachnoid or intraparenchymal hemorrhage associated with mild traumatic brain injury. J. Neurosurg. 123, 649-653.

33. Bajsarowicz, P., Prakash, I., Lamoureux, J., Saluja, R.S., Feyz, M., Maleki, M., and Marcoux, J. (2015). Nonsurgical acute traumatic subdural hematoma: what is the risk? J. Neurosurg. 123, 1176-1183.

34. Bajsarowicz, P., Prakash, I., Lamoureux, J., Saluja, R.S., Feyz, M., Maleki, M., and Marcoux, J. (2012). Traumatic subdural hematomas: conservative treatment outcome and risk factors. Can. J. Neurol. Sci. $3, \mathrm{~S} 20$.

35. Baldawa, S. (2014). Risk factors of delayed surgical evacuation for initially nonoperative acute subdural hematomas following mild head injury. Acta. Neurochir. (Wien) 156, 2363.

36. Basamh, M., Robert, A., Lamoureux, J., Saluja, R.S., and Marcoux, J. (2016). Epidural hematoma treated conservatively: when to expect the worst. Can. J. Neurol. Sci. 43, 74-81.

37. Borczuk, P., Penn, J., Peak, D., and Chang, Y. (2013). Patients with traumatic subarachnoid hemorrhage are at low risk for deterioration or neurosurgical intervention. J. Trauma Acute Care Surg. 74, 15041509.

38. Carlson, A.P., Ramirez, P., Kennedy, G., McLean, A.R., MurrayKrezan, C., and Stippler, M. (2010). Low rate of delayed deterioration requiring surgical treatment in patients transferred to a tertiary care center for mild traumatic brain injury. Neurosurg. Focus 29, E3.

39. Chen, G., Zou, Y., and Yang, D. (2002). The influence of traumatic subarachnoid hemorrhage on prognosis of head injury. Chin. J. Traumatol. 5, 169-171.

40. Choudhry, O., Prestigiacomo, C., Shukla, P., Gala, N., and Sifri, Z. (2012). Delayed neurologic deterioration following mild head injury: etiology, temporal course and outcomes. J. Neurosurg. 117, A422.

41. Choudhry, O.J., Prestigiacomo, C.J., Gala, N., Slasky, S., and Sifri, Z.C (2013). Delayed neurological deterioration after mild head injury: cause, temporal course, and outcomes. Neurosurgery 73, 753-760.

42. Deepika, A., Munivenkatappa, A., Devi, B.I., and Shukla, D. (2013). Does isolated traumatic subarachnoid hemorrhage affect outcome in patients with mild traumatic brain injury? J. Head Trauma Rehabil. $28,442-445$.
43. Flaherty, S.K., Edlow, J.A., Bragg, A.F., Vachha, B.A., Levenson, R.B., and Pope, J.V. (2013). Early results do all patients with traumatic intracranial hemorrhage need hospital admission? Acad. Emerg. Med. 1), S28-S29.

44. Gore, A., Mau, C.Y., Prestigiacomo, C.J., and Sifri, Z.C. (2015). Mild traumatic brain injury in elderly patients: is routine ICU admission necessary? J. Am. Coll. Surg. 1, S82-S83.

45. Iaccarino, C., Schiavi, P., Picetti, E., Goldoni, M., Cerasti, D., Caspani, M., and Servadei, F. (2014). Patients with brain contusions: predictors of outcome and relationship between radiological and clinical evolution: clinical article. J. Neurosurg. 120, 908-918.

46. Inamasu, J., Nakatsukasa, M., Miyatake, S., and Hirose, Y. (2012). Influence of warfarin and low-dose aspirin on the outcomes of geriatric patients with traumatic intracranial hemorrhage resulting from ground-level fall. Geriatr. Gerontol. Int. 12, 667-672.

47. Jacobs, B., Beems, T., Stulemeijer, M., Van Vugt, A.B., Van Der Vliet, T.M., Borm, G.F., and Vos, P.E. (2010). Outcome prediction in mild traumatic brain injury: age and clinical variables are stronger predictors than CT abnormalities. J. Neurotrauma 27, 655-668.

48. Jiang, J.Y. (2009). Chinese National Head Trauma Data Bank: a preliminary analysis. J. Neurotrauma 26, A25.

49. Jiang, J.Y., Xu, S.Y., Zhou, Z.W., Yang, Y.L., Qing, H.P., Qian, S.K., Yang, X.F., Feng, H., Yu, R.T., Liu, Z.X., Liu, J.M., Yang, H.T., Yang, C.H., Long, L.S., Zhang, J., Zhu, X.J., Huang, Q., Liu, B.Y., Tong, W.S., Sun, X.C., Yang, M.L., Zhang, N., Fang, N.C., Qi, S.T., Song, X.W., Tu, C.J., Ning, W., Wu, T.S., Song, G.L., Tong, Z.Z., Fu, X.A., Fan, Y.J., Ni, X.Y., Cui, J.Z., Liang, E.H., Bao, N., Feng, D.F., Xu, W., Li, W.P., Fu, Z., Wang, Z., Wang, Y.H., Yuan, J.L., Jin, G.L., Chen, L.B., Li, S.T., Sun, Y.H., Zhang, J.L., Lei, T., and Du, H.G. (2013). Head trauma in China. Injury 44, 1453-1457.

50. Joseph, B., Aziz, H., Pandit, V., Kulvatunyou, N., Hashmi, A., Tang, A., Sadoun, M., O'Keeffe, T., Vercruysse, G., Green, D.J., Friese, R.S., and Rhee, P. (2014). A three-year prospective study of repeat head computed tomography in patients with traumatic brain injury. J. Am. Coll. Surg. 219, 45-51.

51. Joseph, B., Aziz, H., Pandit, V., Kulvatunyou, N., O'Keeffe, T., Tang, A., Wynne, J., Hashmi, A., Vercruysse, G., Friese, R.S., and Rhee, P. (2014). Low-dose aspirin therapy is not a reason for repeating head computed tomographic scans in traumatic brain injury: a prospective study. J. Surg. Res. 186, 287-291.

52. Joseph, B., Aziz, H., Sadoun, M., Kulvatunyou, N., Tang, A. O'Keeffe, T., Wynne, J., Gries, L., Green, D.J., Friese, R.S., and Rhee, P. (2013). The acute care surgery model: managing traumatic brain injury without an inpatient neurosurgical consultation. J. Trauma Acute Care Surg. 75, 102-105.

53. Joseph, B., Haider, A.A., Pandit, V., Tang, A., Kulvatunyou, N., O'Keeffe, T., and Rhee, P. (2015). Changing paradigms in the management of 2184 patients with traumatic brain injury. Ann. Surg. 262, 440-446.

54. Joseph, B., Pandit, V., Aziz, H., Kulvatunyou, N., Zangbar, B., Green, D.J., Haider, A., Tang, A., O'Keeffe, T., Gries, L., Friese, R.S., and Rhee, P. (2015). Mild traumatic brain injury defined by Glasgow Coma Scale: is it really mild? Brain Inj. 29, 11-16.

55. Kim, B.J., Park, K.J., Park, D.H., Lim, D.J., Kwon, T.H., Chung, Y.G., and Kang, S.H. (2014). Risk factors of delayed surgical evacuation for initially nonoperative acute subdural hematomas following mild head injury. Acta. Neurochir. 56, 1605-1613.

56. Kim, H., Jin, S.T., Kim, Y.W., Kim, S.R., Park, I.S., and Jo, K.W. (2015). Risk factors for early hemorrhagic progression after traumatic brain injury: a focus on lipid profile. J. Neurotrauma 32, 950955.

57. Klein, Y., Donchik, V., Jaffe, D., Simon, D., Kessel, B., Levy, L., Kashtan, H., and Peleg, K. (2010). Management of patients with traumatic intracranial injury in hospitals without neurosurgical service. J. Trauma Inj. Infect. Crit. Care 69, 544-548.

58. Kreitzer, N., Hart, K., Betham, B., Lindsell, C., and Adeoye, O. (2015). Factors associated with clinical course in mild traumatic brain injury with intracranial hemorrhage. Ann. Emerg. Med. 1, S152.

59. Levy, A.S., Orlando, A., Hawkes, A.P., Salottolo, K., Mains, C.W., and Bar-Or, D. (2011). Should the management of isolated traumatic subarachnoid hemorrhage differ from concussion in the setting of mild traumatic brain injury? J. Trauma Inj. Infect. Crit. Care 71, 1199-1204. 
60. Levy, A.S., Orlando, A., Salottolo, K., Mains, C.W., and Bar-Or, D (2014). Outcomes of a nontransfer protocol for mild traumatic brain injury with abnormal head computed tomography in a rural hospital setting. World Neurosurg. 82, e319-e323.

61. McCutcheon, B.A., Orosco, R.K., Chang, D.C., Salazar, F.R., Talamini, M.A., Maturo, S., and Magit, A. (2013). Outcomes of isolated basilar skull fracture: readmission, meningitis, and cerebrospinal fluid leak. Otolaryngol. Head Neck Surg. 149, 931-939.

62. Nayak, N.V., Medina, B., Patel, K., Homnick, A.T., Mohr, A.M., Livingston, D.H., Prestigiacomo, C.J., and Sifri, Z.C. (2013). Neurologic outcome of minimal head injury patients managed with or without a routine repeat head computed tomography. J. Trauma Acute Care Surg. 75, 273-278.

63. Nishijima, D.K., Haukoos, J.S., Newgard, C.D., Staudenmayer, K., White, N., Slattery, D., Maxim, P.C., Gee, C.A., Hsia, R.Y., Melnikow, J.A., and Holmes, J.F. (2013). Variability of ICU use in adult patients with minor traumatic intracranial hemorrhage. Ann. Emerg. Med. 61, 509-517.

64. Nishijima, D.K., and Holmes, J.F. (2010). A clinical decision rule to predict adult patients with traumatic brain injury who do not need intensive care unit admission. Clin. Transl. Sci. 3, S27.

65. Nishijima, D.K., Melnikow, J., Tancredi, D.J., Shahlaie, K., Utter, G.H., Galante, J.M., Rudisill, N., and Holmes, J.F. (2015). Long-term neurological outcomes in adults with traumatic intracranial hemorrhage admitted to ICU versus floor. West. J. Emerg. Med. 16, 284290.

66. Nishijima, D.K., Sena, M., Galante, J.M., Shahlaie, K., London, J., Melnikow, J., and Holmes, J.F. (2014). Derivation of a clinical decision instrument to identify adult patients with mild traumatic intracranial hemorrhage at low risk for requiring ICU admission. Ann. Emerg. Med. 63, 448-456.

67. Nishijima, D.K., Sena, M.J., and Holmes, J.F. (2011). Identification of low-risk patients with traumatic brain injury and intracrania hemorrhage who do not need intensive care unit admission. J. Trauma Inj. Infect. Crit. Care 70, E101-E107.

68. Nishijima, D.K., Shahlaie, K., Echeverri, A., and Holmes, J.F. (2012). A clinical decision rule to predict adult patients with traumatic intracranial haemorrhage who do not require intensive care unit admission. Injury 43, 1827-1832.

69. Overton, T.L., Shafi, S., Cravens, G.F., and Gandhi, R.R. (2014). Can trauma surgeons manage mild traumatic brain injuries? Am. J. Surg. 208, 806-810

70. Penn, J., Borczuk, P., and Peak, D. (2011). Identification of patients with traumatic intracranial hemorrhage who are at low risk for deterioration or neurosurgical intervention. Ann. Emerg. Med. 1, S287.

71. Quigley, M.R., Chew, B.G., Swartz, C.E., and Wilberger, J.E (2013). The clinical significance of isolated traumatic subarachnoid hemorrhage. J. Trauma Acute Care Surg. 74, 581-584.

72. Rubino, S., Zaman, R.A., Sturge, C.R., Fried, J.G., Desai, A., Simmons, N.E., and Lollis, S.S. (2014). Outpatient follow-up of nonoperative cerebral contusion and traumatic subarachnoid hemorrhage: does repeat head CT alter clinical decision-making? J. Neurosurg. 121, 944-949.

73. Schwed, A.C., Boggs, M.M., Watanabe, D., Plurad, D.S., Putnam, B.A., and Kim, D.Y. (2016). Admission variables associated with a favorable outcome after mild traumatic brain injury. Am. Surg. 82, 898-902.

74. Sharifuddin, A., Adnan, J., Ghani, A.R., and Abdullah, J.M. (2012). The role of repeat head computed tomography in the management of mild traumatic brain injury patients with a positive initial head CT. Med. J. Malaysia 67, 305-308.

75. Sifri, Z.C., Homnick, A.T., Vaynman, A., Lavery, R., Liao, W., Mohr, A., Hauser, C.J., Manniker, A., and Livingston, D. (2006). A prospective evaluation of the value of repeat cranial computed tomography in patients with minimal head injury and an intracranial bleed. J. Trauma Inj. Infect. Crit. Care 61, 862-867.

76. Sumritpradit, P., Setthalikhit, T., and Chumnanvej, S. (2016). Assessment and predicting factors of repeated brain computed tomography in traumatic brain injury patients for risk-stratified care management: a 5-year retrospective study. Neurol. Res. Int. [Epub 2016 Sep. 15].

77. Velmahos, G.C., Gervasini, A., Petrovick, L., Dorer, D.J., Doran, M.E., Spaniolas, K., Alam, H.B., De Moya, M., Borges, L.F., and Conn, A.K. (2006). Routine repeat head CT for minimal head injury is unnecessary. J. Trauma Injury Infect. Crit. Care 60, 494-499; discussion 499-501.
78. Washington, C.W., and Grubb Jr, R.L. (2012). Are routine repeat imaging and intensive care unit admission necessary in mild traumatic brain injury? Clinical article. J. Neurosurg. 116, 549-557.

79. Wu, C., Orringer, D.A., Lau, D., and Fletcher, J.J. (2012). Cumulative incidence and predictors of neurosurgical interventions following nonsevere traumatic brain injury with mildly abnormal head imaging findings. J. Trauma Acute Care Surg. 73, 1247-1253.

80. Yuan, F., Ding, J., Chen, H., Guo, Y., Wang, G., Gao, W.W., Chen, S.W., and Tian, H.L. (2012). Predicting progressive hemorrhagic injury after traumatic brain injury: derivation and validation of a risk score based on admission characteristics. J. Neurotrauma 29, 21372142 .

81. Zare, M.A., Ahmadi, K., Zadegan, S.A., Farsi, D., and RahimiMovaghar, V. (2013). Effects of brain contusion on mild traumatic brain-injured patients. Int. J. Neurosci. 123, 65-69.

82. Zhao, T., Mejaddam, A.Y., Chang, Y., Demoya, M.A., King, D.R., Yeh, D.D., Kaafarani, H.M.A., Alam, H.B., and Velmahos, G.C. (2016). Admissions for isolated nonoperative mild head injuries: sharing the burden among trauma surgery, neurosurgery, and neurology. J. Trauma Acute Care Surg. 81, 743-747.

83. Park, H.K., Joo, W.I., Chough, C.K., Cho, C.B., Lee, K.J., and Rha, H.K. (2009). The clinical efficacy of repeat brain computed tomography in patients with traumatic intracranial haemorrhage within 24 hours after blunt head injury. Br. J. Neurosurg. 23, 617-621.

84. Schuster, R., and Waxman, K. (2005). Is repeated head computed tomography necessary for traumatic intracranial hemorrhage? Am. Surg. 71, 701-704.

85. Smith, J.S., Chang, E.F., Rosenthal, G., Meeker, M., von Koch, C., Manley, G.T., and Holland, M.C. (2007). The role of early follow-up computed tomography imaging in the management of traumatic brain injury patients with intracranial hemorrhage. J. Trauma Inj. Infect. Crit. Care 63, 75-82.

86. Kreitzer, N., Lyons, M.S., Hart, K., Lindsell, C.J., Chung, S., Yick, A., and Bonomo, J. (2014). Repeat neuroimaging of mild traumatic brain-injured patients with acute traumatic intracranial hemorrhage: clinical outcomes and radiographic features. Acad. Emerg. Med. 21, 1084-1091.

87. Fabbri, A., Servadei, F., Marchesini, G., Bronzoni, C., Montesi, D., and Arietta, L. (2013). Antiplatelet therapy and the outcome of subjects with intracranial injury: The Italian SIMEU study. Crit. Care 17, R53.

88. Choudhry, O., Sifri, Z., Yonclas, P., and Livingston, D. (2010). Acute neurologic deterioration following MTBI: timings, etiology, and outcomes. Brain Inj. 24, 341-342.

89. Tong, W.-S., Zheng, P., Zeng, J.-S., Guo, Y.-J., Yang, W.-J., Li, G.Y., He, B., Yu, H., Li, Y.-S., Tang, X.-F., Lin, T.-S., and Xu, J.-F. (2012). Prognosis analysis and risk factors related to progressive intracranial haemorrhage in patients with acute traumatic brain injury...[corrected] [published erratum appears in Brain Inj. 2013;27(2):251]. Brain Inj. 26, 1136-1142.

90. Ding, J., Yuan, F., Guo, Y., Chen, S.W., Gao, W.W., Wang, G., Cao, H.L., Ju, S.M., Chen, H., Zhang, P.Q., and Tian, H.L. (2012). A prospective clinical study of routine repeat computed tomography (CT) after traumatic brain injury (TBI). Brain Inj. 26, 1211-1216.

91. Yadav, Y.R., Basoor, A., Jain, G., and Nelson, A. (2006). Expanding traumatic intracerebral contusion/hematoma. Neurol. India 54, 377381.

92. Cohen, D.B., Rinker, C., and Wilberger, J.E. (2006). Traumatic brain injury in anticoagulated patients. J. Trauma Inj. Infect. Crit. Care 60, 553-557.

93. Beynon, C., Potzy, A., Sakowitz, O.W., and Unterberg, A.W. (2015). Rivaroxaban and intracranial haemorrhage after mild traumatic brain injury: a dangerous combination? Clin. Neurol. Neurosurg. 136, 73-78.

94. Lawrence, T., Helmy, A., Bouamra, O., Woodford, M., Lecky, F., and Hutchinson, P.J. (2016). Traumatic brain injury in England and Wales: prospective audit of epidemiology, complications and standardised mortality. BMJ Open 6, e012197.

95. Kehoe, A., Smith, J.E., Bouamra, O., Edwards, A., Yates, D., and Lecky, F. (2016). Older patients with traumatic brain injury present with a higher GCS score than younger patients for a given severity of injury. Emerg. Med. J33, 381-385.

96. Lesko, M., Bouamra, O., O'Brien, S., and Lecky, F. (2012). Prognostic value of various intracranial pathologies in traumatic brain injury. Eur. J. Trauma Emerg. Surg. 38, 25-32. 
97. Huynh, T., Jacobs, D.G., Dix, S., Sing, R.F., Miles, W.S., and Thomason, M.H. (2006). Utility of neurosurgical consultation for mild traumatic brain injury. Am. Surg. 72, 1162-1165; discussion1166-1167.

98. Sweeney, T.E., Salles, A., Harris, O.A., Spain, D.A., and Staudenmayer, K.L. (2015). Prediction of neurosurgical intervention after mild traumatic brain injury using the national trauma data bank. World J. Emerg. Surg. 10, 23.

99. Bee, T.K., Magnotti, L.J., Croce, M.A., Maish, G.O., Minard, G., Schroeppel, T.J., Zarzaur, B.L., and Fabian, T.C. (2009). Necessity of repeat head CT and ICU monitoring in patients with minimal brain injury. J. Trauma 66, 1015-1018.

100. Shih, F.Y., Chang, H.H., Wang, H.C., Lee, T.H., Lin, Y.J., Lin, W.C., Chen, W.F., Ho, J.T., and Lu, C.H. (2016). Risk factors for delayed neuro-surgical intervention in patients with acute mild traumatic brain injury and intracranial hemorrhage. World J. Emerg. Surg. 11, 13.

101. Bardes, J.M., Turner, J., Bonasso, P., Hobbs, G., and Wilson, A. (2016). Delineation of criteria for admission to step down in the mild traumatic brain injury patient. Am. Surg. 82, 36-40.

102. Sifri, Z.C., Livingston, D.H., Lavery, R.F., Homnick, A.T., Mosenthal, A.C., Mohr, A.M., and Hauser, C.J. (2004). Value of repeat cranial computed axial tomography scanning in patients with minimal head injury. Am. J. Surg. 187, 338-342.

103. Phelan, H.A., Richter, A.A., Scott, W.W., Pruitt, J.H., Madden, C.J., Rickert, K.L., and Wolf, S.E. (2014). Does isolated traumatic subarachnoid hemorrhage merit a lower intensity level of observation than other traumatic brain injury? J. Neurotrauma 31, 1733-1736.

104. Homnick, A., Sifri, Z., Yonclas, P., Mohr, A., and Livingston, D. (2012). The temporal course of intracranial haemorrhage progression: how long is observation necessary? Injury 43, 2122-2125.

105. Stein, S.C., Fabbri, A., and Servadei, F. (2008). Routine serial computed tomographic scans in mild traumatic brain injury: when are they cost-effective? J. Trauma 65, 66-72.

106. Nasir, S., and Hussain, M. (2011). Repeat cranial tomography in patients with mild head injury and stable neurological examinationa perspective from a developing country. Chin. J. Traumatol. 14, 297-300.

107. Kessel Boris, I.A., Zeina Abdel Rauf, Nachtigal Alicia, Korin Alexander, Khashan T RN, and Ricardo Alfici. (2013). Is routine brain CT scan performed for early follow up head trauma patients with GCS14-15 always justified? J. Trauma Treat. 2, 174.

108. Pruitt, P., Penn, J., Peak, D., and Borczuk, P. (2016). Identifying patients with mild traumatic intracranial hemorrhage at low risk of decompensation who are safe for ED observation. Am. J. Emerg. Med. 35, 255-259.

109. Joseph, B., Friese, R.S., Sadoun, M., Aziz, H., Kulvatunyou, N., Pandit, V., Wynne, J., Tang, A., O'Keeffe, T., and Rhee, P. (2014). The BIG (brain injury guidelines) project: defining the management of traumatic brain injury by acute care surgeons. J. Trauma Acute Care Surg. 76, 965-969.

110. Borovich, B., Braun, J., Guilburd, J.N., Zaaroor, M., Michich, M., Levy, L., Lemberger, A., Grushkiewicz, I., Feinsod, M., and Schachter, I. (1985). Delayed onset of traumatic extradural hematoma. J. Neurosurg. 63, 30-34.

111. Knuckey, N.W., Gelbard, S., and Epstein, M.H. (1989). The management of "asymptomatic" epidural hematomas. A prospective study. J. Neurosurg. 70, 392-396.

112. Chen, T.Y., Wong, C.W., Chang, C.N., Lui, T.N., Cheng, W.C., Tsai, M.D., and Lin, T.K. (1993). The expectant treatment of "asymptomatic" supratentorial epidural hematomas. Neurosurgery 32, 176179; discussion 179 .

113. Mertol, T., Guner, M., Acar, U., Atabay, H., and Kirisoglu, U. (1991). Delayed traumatic intracerebral hematoma. Br. J. Neurosurg. 5, 491-498.

114. Brown, C.V., Zada, G., Salim, A., Inaba, K., Kasotakis, G., Hadjizacharia, P., Demetriades, D., and Rhee, P. (2007). Indications for routine repeat head computed tomography (CT) stratified by severity of traumatic brain injury. J. Trauma 62, 1339-1344; discussion 1344-1335.

115. Brown, C.V.R., Weng, J., Oh, D., Salim, A., Kasotakis, G., Demetriades, D., Velmahos, G.C., and Rhee, P. (2004). Does routine serial computed tomography of the head influence management of traumatic brain injury? A prospective evaluation. J. Trauma Acute Care Surg. 57, 939-943.
116. Chieregato, A., Fainardi, E., Morselli-Labate, A.M., Antonelli, V., Compagnone, C., Targa, L., Kraus, J., and Servadei, F. (2005). Factors associated with neurological outcome and lesion progression in traumatic subarachnoid hemorrhage patients. Neurosurg. 56, 671680; discussion 671-680.

117. Fainardi, E., Chieregato, A., Antonelli, V., Fagioli, L., and Servadei, F. (2004). Time course of CT evolution in traumatic subarachnoid haemorrhage: a study of 141 patients. Acta. Neurochir. (Wien) 146, 257-263; discussion 263

118. Karasu, A., Sabanci, P.A., Izgi, N., Imer, M., Sencer, A., Cansever, T., and Canbolat, A. (2008). Traumatic epidural hematomas of the posterior cranial fossa. Surg. Neurol. 69, 247-251; dicussion 251-242.

119. Roka, Y.B., Kumar, P., Bista, P., Sharma, G.R., Adhikari, D., Khadka, N.K., and Devkota, U.P. (2008). Role of repeat CT scan head in initially inoperable cases of traumatic head injury. Nepal Med. Coll. J. 10, 225-229.

120. Turedi, S., Hasanbasoglu, A., Gunduz, A., and Yandi, M. (2008) Clinical decision instruments for CT scan in minor head trauma. J. Emerg. Med. 34, 253-259.

121. Connon, F.F, Nanadarian, B., Ee, J.L., Drummond, K.J., and Miller, J.A. (2011). Do routinely repeated computed tomography scans in traumatic brain injury influence management? A prospective observational study in a level 1 trauma center. Ann. Surg. 254, 1028-1031.

122. Chang, E.F., Meeker, M., and Holland, M.C. (2006). Acute traumatic intraparenchymal hemorrhage: risk factors for progression in the early post-injury period. Neurosurg. 58, 647-656; discussion 647-656.

123. Chao, A., Pearl, J., Perdue, P., Wang, D., Bridgeman, A., Kennedy, S., Ling, G., and Rhee, P. (2001). Utility of routine serial computed tomography for blunt intracranial injury. J. Trauma 51, 870-875; discussion 875-876.

124. Sullivan, T.P., Jarvik, J.G., and Cohen, W.A. (1999). Follow-up of conservatively managed epidural hematomas: implications for timing of repeat CT. AJNR Am. J. Neuroradiol. 20, 107-113.

125. Sifri, Z.C., Nayak, N., Homnick, A.T., Mohr, A.A., Yonclas, P., and Livingston, D.H. (2011). Utility of repeat head computed tomography in patients with an abnormal neurologic examination after minimal head injury. J. Trauma 71, 1605-1610.

126. Innocenti, F., Del Taglia, B., Tassinari, I., Trausi, F., Conti, A., Zanobetti, M., and Pini, R. (2016). Utility of repeat head computed tomography after mild head trauma: influence on short- and long-term prognosis and health-related quality of life. Intern. Emerg. Med. 12, 81-89.

127. Muszynski, C.A., Hayman, L.A., Weingarten, K., Prow, H.W., Cole, J.W., and Contant, C.F. (1999). Conservative management of extraaxial hematomas diagnosed by CT. Neuroradiology $41,875-881$.

128. Patel, N.Y., Hoyt, D.B., Nakaji, P., Marshall, L., Holbrook, T., Coimbra, R., Winchell, R.J., and Mikulaschek, A.W. (2000). Traumatic brain injury: patterns of failure of nonoperative management. J. Trauma 48, 367-374; discussion 374-365.

129. Lingsma, H.F., Yue, J.K., Maas, A.I., Steyerberg, E.W., Manley, G.T., and TRACK-TBI Investigators. (2015). Outcome prediction after mild and complicated mild traumatic brain injury: external validation of existing models and identification of new predictors using the TRACK-TBI pilot study. J. Neurotrauma 32, 83-94.

130. Darby, G.C. (2015). Mild traumatic brain injury: the feasibility of reducing repetitive head $\mathrm{CT}$ scans in stable patients. UC Irvine Electronic Theses and Dissertations. https://escholarship.org/uc/item/ 8mx0198f (last accessed January 15, 2017).

131. Wong, C.W. (1995). Criteria for conservative treatment of supratentorial acute subdural haematomas. Acta. Neurochir. (Wien) 135, $38-43$.

132. Offner, P.J., Pham, B., and Hawkes, A. (2006). Nonoperative management of acute epidural hematomas: a "no-brainer." Am. J. Surg. $192,801-805$.

133. Wong, C.W. (1995). CT and clinical criteria for conservative treatment of supratentorial traumatic intracerebral haematomas. Acta. Neurochir. (Wien) 135, 131-135.

134. Bhau, K.S., Bhau, S.S., Dhar, S., Kachroo, S.L., Babu, M.L., and Chrungoo, R.K. (2010). Traumatic extradural hematoma: role of nonsurgical management and reasons for conversion. Indian J. Surg. 72, $124-129$.

135. Gaetani, P., Tancioni, F., Tartara, F., Carnevale, L., Brambilla, G., Mille, T., and Rodriguez y Baena, R. (1995). Prognostic value of the amount of post-traumatic subarachnoid haemorrhage in a six month follow up period. J. Neurol. Neurosurg. Psychiatry 59, 635-637. 
136. Greene, K.A., Marciano, F.F., Johnson, B.A., Jacobowitz, R., Spetzler, R.F., and Harrington, T.R. (1995). Impact of traumatic subarachnoid hemorrhage on outcome in nonpenetrating head injury. Part I: a proposed computerized tomography grading scale. J. Neurosurg. 83, 445-452.

137. Son, S., Yoo, C.J., Lee, S.G., Kim, E.Y., Park, C.W., and Kim, W.K (2013). Natural course of initially non-operated cases of acute subdural hematoma : the risk factors of hematoma progression. J. Korean Neurosurg. Soc. 54, 211-219.

138. Balmiki, P.K., Chourasia, A.K., and Chourasia, I.D. (2015). Role of sequel CT scan head after twenty four hours of traumatic head injury. Int. Surg. J. 2, 194-199.

139. Fabbri, A., Servadei, F., Marchesini, G., Stein, S.C., and Vandelli, A. (2008). Observational approach to subjects with mild-to-moderate head injury and initial non-neurosurgical lesions. J. Neurol. Neurosurg. Psychiatry 79, 1180-1185.

140. Zhang, D., Gong, S., Jin, H., Wang, J., Sheng, P., Zou, W., Dong, Y., and Hou, L. (2015). Coagulation parameters and risk of progressive hemorrhagic injury after traumatic brain injury: a systematic review and meta-analysis. Biomed. Res. Int. 2015, 261825.

141. Caterino, J.M., Raubenolt, A., and Cudnik, M.T. (2011). Modification of Glasgow Coma Scale criteria for injured elders. Acad. Emerg. Med. 18, 1014-1021.

142. Shea, B.J., Hamel, C., Wells, G.A., Bouter, L.M., Kristjansson, E., Grimshaw, J., Henry, D.A., and Boers, M. (2009). AMSTAR is a reliable and valid measurement tool to assess the methodological quality of systematic reviews. J. Clin. Epidemiol. 62, 1013-1020.

143. Whiting, P., Savovic, J., Higgins, J.P., Caldwell, D.M., Reeves, B.C., Shea, B., Davies, P., Kleijnen, J., Churchill, R., and group, R. (2016).
ROBIS: A newtool to assess risk of bias in systematic reviews was developed. J. Clin. Epidemiol. 69, 225-234.

144. Carroll, L.J., Cassidy, J.D., Cancelliere, C., Cote, P., Hincapie, C.A., Kristman, V.L., Holm, L.W., Borg, J., Nygren-de Boussard, C., and Hartvigsen, J. (2014). Systematic review of the prognosis after mild traumatic brain injury in adults: cognitive, psychiatric, and mortality outcomes: results of the International Collaboration on Mild Traumatic Brain Injury Prognosis. Arch. Phys. Med. Rehabil. 95, S152S173.

145. Stiell, I., Wells, G., Laupacic, A., Brison, R., Verbeek, R., Vandemheen, K., and Naylor, C.D. (1995). Multicentre trial to introduce the Ottawa ankle rules for use of radiography in acute ankle injuries. Multicentre Ankle Rule Study Group. BMJ 311, 594-597.

146. Wolf, S.J., McCubbin, T.R., Feldhaus, K.M., Faragher, J.P., and Adcock, D.M. (2004). Prospective validation of Wells Criteria in the evaluation of patients with suspected pulmonary embolism. Ann. Emerg. Med. 44, 503-510.

Address correspondence to:

Carl Marincowitz, MB BChir, MSc, BA

Hull York Medical School

Allam Medical Building

University of Hull

Hull HU6 7RX

United Kingdom

E-mail: carl.marincowitz@hyms.ac.uk 